\title{
A comparison between cost optimality and return on investment for energy retrofit in buildings-A real options perspective
}

\author{
Sérgio Fernando Tadeu ${ }^{\mathrm{a}, *}$, Rafael F. Alexandre ${ }^{\mathrm{b}, 1}$, António J.B. Tadeu ${ }^{\mathrm{a}}$, \\ Carlos Henggeler Antunes ${ }^{c, d, 2}$, Nuno A.V. Simões ${ }^{a}$, Patrícia Pereira da Silva ${ }^{\mathrm{d}, e, 3}$ \\ a Department of Civil Engineering-FCTUC, University of Coimbra, Rua Sílvio Lima-Pólo II, 3030-790 Coimbra, Portugal \\ ${ }^{\mathrm{b}}$ Department of Computer and Systems, Federal University of Ouro Preto, Rua 37, 115, 35931-008 João Monlevade, Brazil

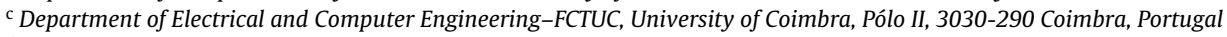 \\ d INESC Coimbra, Rua Antero de Quental, 199, 3030-030 Coimbra, Portugal \\ e Faculty of Economics, University of Coimbra, Av. Dias da Silva, 165, 3004-512 Coimbra, Portugal
}

\section{A R T I C L E I N F O}

\section{Article history:}

Received 7 July 2015

Received in revised form

11 November 2015

Accepted 13 November 2015

Available online 28 November 2015

\section{Keywords:}

Cost optimality

Real options

Energy retrofit

Genetic algorithms

Sustainable buildings

\begin{abstract}
A B S T R A C T
European Union (EU) regulations aim to ensure that the energy performance of buildings meets the cost-optimality criteria for energy efficiency measures. The methodological framework proposed in EU Delegated Regulation 244 is addressed to national authorities (not investors); the optimal cost level is calculated to develop regulations applicable at domestic level. Despite the complexity and the large number of possible combinations of economically viable efficiency measures, the real options for improving energy performance available to decision makers in building retrofit can be established. Our study considers a multi-objective optimization approach to identify the minimum global cost and primary energy needs of 154,000 combinations of energy efficiency measures. The proposed model is solved by the NSGAII multi-objective evolutionary algorithm. As a result, the cost-optimal levels and a return on investment approach are compared for a set of suitable solutions for a reference building. Eighteen combinations of retrofit measures are selected and an analysis of the influence of real options on investments is proposed. We show that a sound methodological approach to determining the advantages of this type of investment should be offered so that Member States can provide valuable information and ensure that the minimum requirements are profitable to most investors.
\end{abstract}

(c) 2015 Elsevier Ltd. All rights reserved.

\section{Introduction}

Following the Energy Performance of Buildings Directive (EPBD) (EPBD, 2010), Member States shall comply with the Delegated Regulation 244/2012 (EU, 2012) to calculate the cost of energy efficiency measures applied to reference buildings over the estimated economic life cycle. Common information, such as long-term estimates of carbon prices and the evolution of energy prices (expected

\footnotetext{
* Corresponding author. Tel.: +351913734586.

E-mail addresses: sergio.tadeu@itecons.uc.pt (S.F. Tadeu),

rfalexandre@decea.ufop.br (R.F. Alexandre), tadeu@itecons.uc.pt (A.J.B. Tadeu),

ch@deec.uc.pt (C.H. Antunes), nasimoes@itecons.uc.pt (N.A.V.Simões), patsilva@fe.uc.pt (P.P.d. Silva).

URLs: http://www.uc.pt/fctuc/dec. (S.F. Tadeu), http://www.uc.pt/fctuc/dec. (A.J.B. Tadeu), http://www.uc.pt/fctuc/dec. (N.A.V. Simões).

1 web: http://www.ufop.br

2 web: http://www.uc.pt/fctuc/deec

3 web: http://www.uc.pt/fe.uc.pt
}

up to 2050), is provided by the European Commission (Eurostat-EU Energy, 2013; Eurostat, 2014).

In July 2013, Portugal sent the nationwide report (DGEG, 2013) specified in Article 6 of the Delegated Regulation (EU, 2012) containing the data and assumptions used for cost-optimal calculations. However, this report only refers to new buildings, which annually represented less than $1 \%$ of Portugal's building stock (INE, 2013). The cost-optimal measures were selected using the Monte Carlo simulation techniques. It neither includes a sensitivity analysis of the discount rates and the evolution of energy prices, nor indicates the use of renewable energy sources required in (EU, 2012).

When transposing the methodological framework proposed in EPBD (2010), the Portuguese legislation established a methodology for calculating the economic feasibility (REH, 2013). However, this methodology only applies to wholesale and retail building trade services in the following situations: (1) design and construction of new buildings; (2) "major renovation" of the envelope or technical systems in existing buildings; and (3) energy assessment and 
maintenance of new and existing buildings undergoing major renovation under the energy certification system for buildings.

The Order (extract) 15793-L/2013 (Despacho, 2013) states that projects are contingent upon economic feasibility, with mandatory implementation when the relevant study shows that there are no technical, legal or administrative limitations or constraints on the installation and the simple payback period is eight years or less.

The term "major renovations" mentioned by EPBD is transposed into the national context as changes in the envelope and/or technical systems amounting to $25 \%$ or more of the building market value. Thus, an investment analysis to assess profitability should not be restricted to a mere simple payback period study. However, despite the inherent risk and uncertainty, energy retrofit projects offer options and flexibility for making subsequent decisions that affect the future cash flows and the project life cycle.

In short, Portugal faces the same difficulties of other countries in the EU-28: the large amount of possible combinations of efficiency measures for energy retrofit of buildings hinders the selection of the cost-optimal ones and the lack of a clear policy does not attract private investment.

The aim of this study is to contextualize the real options in energy retrofit of buildings and show the best options on the return on investment criteria (ROI), based on Portuguese market prices. The goal is not to assign quantitative and absolute values to these options, but to value measures more profitable than the business as usual (BAU) scenario. A multi-objective optimization problem designed to minimize the global cost and primary energy needs of the energy efficiency measures is developed. Section 2 discusses the risks, uncertainties and relevance of applying real options theory to cost optimality studies on the energy retrofit of buildings. The methodology and a case study are presented in Section 3. In Section 4, illustrative results are presented and their implications from the perspective of real options are discussed. Some conclusions are drawn in Section 5.

\section{Risk, uncertainty and real options in energy retrofit of buildings}

The evidence of financial gains of energy efficiency investments in existing buildings is to our knowledge still rather limited (Christersson, Vimpari, \& Junnila, 2015). The energy retrofit of buildings involves irreversibility issues and the possibility of deferral associated with the investment. This investment can be considered low risk, but also with little or no liquidity. Traditional investment analysis criteria, such as the net present value (NPV), tend to underestimate its value since, in general, they do not incorporate operational flexibility issues and other strategic factors in the calculation process, in particular the possibility of deferral (Soares, 1996).

Although there is some commitment to keep a given solution for a long time once the decision to implement has been made, it is possible to revert previous decisions when circumstances and/or the technology change. For example, heating systems, whether conventional or based on renewable energy sources (RES), may be replaced by an alternative system at the end of their life cycle, appreciably shorter than the 30-year period recommended in (EU, 2012). Building owners can then decide to redirect their investment, which denotes a certain strategic adaptability. Therefore, real options increase the value of the project and should be added to the NPV. The greater the number of options and the associated uncertainty, the higher the project value (Silva, 1999).

The selection of actions to improve energy efficiency in buildings is a problem involving multiple, incommensurate and generally conflicting axes of evaluation of the merits of those actions. These problems may be tackled using multi-objective optimization models, in which the set of potential alternatives is implicitly defined by constraints defining a feasible region and multiple objective functions are optimized, or multi-criteria decision analysis, in which the alternatives are explicitly known apriori to be appraised by (qualitative and/or quantitative) multiple criteria. Simulation techniques are also used to deal with this problem, in general focusing on particular aspects rather than following a global approach (Asadi, Silva, Antunes, Dias, \& Glicksman, 2014; Caccavelli \& Gugerli, 2002; Chidiac, Catania, \& Morofsky, 2011a; Chidiac, Catania, Morofsky, \& Foo, 2011b; Diakaki, Grigoroudis, \& Kolokotsa, 2008; Doukas, Nychtis, \& Psarras, 2009; Soares et al., in press; Verbruggen, Al Marchohi, \& Janssens, 2011).

It is not always possible to establish numerical techniques either directly addressing the stochastic process (Monte Carlo simulation, for example) or based on the resulting differential equations (Pindyck, 1988). Monte Carlo techniques compute the expected value and the dispersion (standard deviation) of a variable (for example, cash flow), considering the variation range and the probability distribution of a set of uncertain parameters. However, these techniques do not distinguish between technical and economic uncertainty, so their use in cost-optimal approaches is not appropriate. It should be noted that future economic uncertainty overlaps technical performance uncertainty, so it cannot be easily defined in a probabilistic manner (Rysanek \& Choudhary, 2013). The Monte Carlo simulation techniques are therefore limited and cannot optimize the profitability of energy efficiency measures in buildings. Instead of simulating all the combinations, the computation time can be significantly reduced through the use of genetic algorithms to cope with the combinatorial nature of the problem.

A range of real options can be considered in investments in the energy retrofit of buildings. Building owners may decide to defer, abandon, contract, expand or exchange a particular solution for insulation, heating, cooling, domestic hot water (DHW) or use of RES on-site as explained below.

Option of waiting or deferral: when there is no regulatory requirement, the building owner can postpone the implementation of a specific energy efficiency measure. It is straightforward to determine the optimal investment time when there is no uncertainty, since it is sufficient to calculate the project NPV associated with various start dates and select the one with the higher value. However, this simple rule does not apply in an uncertain context (Silva, 1999). One example is the uncertainty of future interest rates that affect the required return rate (the cost of capital) used as the discount rate. Dealing with uncertainty is still more difficult when different scenarios for the evolution of energy prices are considered. The combination of all these issues will determine the attractiveness of energy efficiency measures. For example, the replacement of systems may involve a waiting value, especially for fuel switching. In the case of highly volatile prices, waiting becomes a more profitable option. However, there is no waiting value in building envelope retrofit when energy price presents a moderate and smooth increasing (Kumbaroglu \& Madlener, 2012).

Option to abandon or exchange: technically, abandonment occurs when the decision maker chooses waiving the project still in the investment start-up phase, and exchange is waiving in the operational phase. The optimal time of this waiver is the point where, when comparing future expected cash flows, immediate abandonment has the highest adjusted value (Robichek \& Van Horne, 1967). In the case of rehabilitation investment, the abandonment option appears meaningless.

Option to contract or expand: the expansion option has various applications in pilot projects and research and development projects. These projects can have negative NPV in a first approach, but they can turn out to be quite valuable with a relatively small investment, since they can collect information leading to larger investments and less technical uncertainty. In energy retrofit, this 
can be represented, for example, by installing insulation at different stages or by modules. The results can be assessed by energy audits (Dall, Speccher, \& Bruni, 2012) and when experiences are good there are arguments for the expansion of investment. In the opposite scenario, decision makers may not invest in subsequent steps and shrink the investment initially planned. Similarly, it is possible to implement RES on a small scale and expand them as the energy production potential is confirmed.

In summary, the options framework indicates that, all other things being equal, the value of management flexibility (premium option) is greater under uncertainty; it may increase in periods of high interest rates and can grow in longer investment projects or those that can be deferred. Greater uncertainty, higher interest rates or leaving more time before the implementation of a project (even indicating delay in receiving or saving cash flows) do not necessarily represent a worse investment opportunity (Silva, 1999).

We emphasize that the time of retrofit implementation as well as the reinforcement of the energy performance level of building retrofitting, as stated in the EPBD or in national regulations, shall be taken as constraints over which the owner or investor does not have much freedom to defer or delay when it comes to deferring or delaying implementation of the energy efficiency measures.

\section{Case study}

The building under study is a 2-bedroom single-family dwelling built before 1960 . The calculations use climate data from the city of Amarante, located in central region of Portugal, with $1570^{\circ} \mathrm{C}$ of heating degree days (HDD) (REH, 2013). It was defined as a reference building representative of detached houses from this period of construction. The geometric and thermal characteristics of this building were established using statistical data provided by the National Agency for Energy (ADENE), available in the Energy Certification System (ECS) database (DGEG, 2013), which contains more than 800,000 certificates.

This building occupies $80 \mathrm{~m}^{2}$, it has a heating system with nominal efficiency of 1.00 and a DHW system with nominal efficiency of 0.60 . The original thermal transmittance values ( $U$ value) for the roof, walls and ground floor are 2.80, 2.00 and $1.65\left[\mathrm{~W} /\left(\mathrm{m}^{2}{ }^{\circ} \mathrm{C}\right)\right]$, respectively. The thermal insulation option is expanded polystyrene (EPS) with thicknesses ranging from 30 to $180 \mathrm{~mm}$. It is assumed that insulation is applied to the exterior façade, the roofing slab and the ground floor. The reference building has single-glazed wooden framed windows with a solar heat gain coefficient $g_{\mathrm{w}}$ of 0.85 and a thermal transmittance value $U$ of 5.10 $\left[\mathrm{W} /\left(\mathrm{m}^{2}{ }^{\circ} \mathrm{C}\right)\right]$, which are replaced in some retrofit packages (set of measures to be applied to the building). The options for windows replacement have $U$ values ranging from 1.21 to $2.45\left[\mathrm{~W} /\left(\mathrm{m}^{2}{ }^{\circ} \mathrm{C}\right)\right]$ and coefficients $g_{\mathrm{w}}$ from 0.30 to 0.59 .

The energy retrofit packages combine 10 solutions for roof, 10 for exterior walls and 10 for ground floor thermal insulation, 11 options for windows replacement and the use of 4 different heating and DHW systems, plus 4 options for RES. A total of 154,000 packages were obtained discounting 22,000 adverse combinations. The heating and DHW systems defined as energy efficiency retrofit measures are an air conditioner $(A C)$ (for heating only), a biomass boiler (BM) and a gas boiler (GB) for both heating and DHW. The technical performance details were based on the most widely used systems in the Portuguese market (CYPE, 2014) and an annual maintenance cost of $1 \%$ of the initial investment was considered. Table 1 shows the possible combinations of heating and DHW systems. These set of combinations were compared with the heating and DHW systems defined for the reference building (electric heater, $\mathrm{EH}$, and gas water heater, GWH). The options for RES are a solar thermal thermosyphon system-ST T, a solar thermal forced circulation system-ST C, and a photovoltaic panel-PV, as shown in Table 2. The PV production is for self-consumption, which means that there is no feed-in tariff. The system uses batteries to store the surplus electricity produced. The efficiencies of renewable energy sources are indicated in Portuguese legislation (REH, 2013) and the system sizes were selected to prevent waste of energy in all the simulated scenarios.

\subsection{Methodology}

The energy needs were calculated using the seasonal methodology of EN ISO 13790:2008 (European, 2008), as it was adopted in Portugal. The calculation is first performed assuming permanent use of heating systems throughout the winter. However, since the real energy consumption is lower than the estimated value obtained with the seasonal method, a consumption reduction factor was considered taking into account the heating habits nationwide. Considering the recent trend of growing use of electrical heating systems and the improvement in their efficiency, this energy source was used as a reference. According to the latest survey (2010) by the national statistics institute (ICESD, 2010) (Instituto Nacional de Estatística, 2011), 51.7\% of households used electricity for heating. The annual electricity consumption for heating per housing unit was 418.6 [ $\mathrm{kWh}$ ] (0.036 [toe]), for buildings with an average area of $106.6\left[\mathrm{~m}^{2}\right]$ and an average heated area of $50.6\left[\mathrm{~m}^{2}\right](47.5 \%$ of the total area). Thus, the actual annual consumption of final energy was $8.3\left[\mathrm{kWh} / \mathrm{m}^{2}\right]$ of the heated area.

Table 1

Heating and DHW system combinations.

\begin{tabular}{|c|c|c|c|c|c|c|c|c|c|c|c|}
\hline \multicolumn{6}{|c|}{ Heating system } & \multicolumn{6}{|c|}{ DHW system } \\
\hline $\mathrm{h}, k$ & Equipment & Fuel & Efficiency & Power $[\mathrm{kW}]$ & Investment [€] & $\mathrm{w}, k$ & Equipment & Fuel & Efficiency & Power [kW] & Investment $[€]$ \\
\hline $\mathrm{h}, 1$ & Electric heater & Electricity & 1.00 & 9.6 & 908 & $\mathrm{w}, 1$ & Gas water heater & Gas & 0.60 & 9.4 & 325 \\
\hline $\mathrm{h}, 2$ & Air conditioner & Electricity & 4.30 & 8.6 & 4948 & $\mathrm{w}, 2$ & Gas water heater & Gas & 0.78 & 9.4 & 542 \\
\hline h,3 & Biomass boiler & Pellets & 0.92 & $4.8-16$ & 4776 & $w, 3$ & Biomass boiler & Pellets & 0.92 & $4.8-16$ & 3053 \\
\hline $\mathrm{h}, 4$ & Gas boiler & Gas & 0.93 & $7-23.6$ & 1520 & $\mathrm{w}, 4$ & Gas boiler & Gas & 0.83 & $7-23.6$ & 972 \\
\hline
\end{tabular}

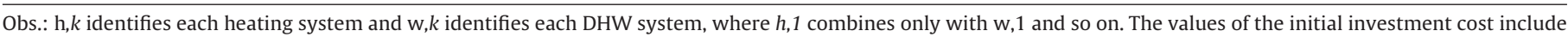
taxes and fees. It was assumed that $39 \%$ of the investment associated with BM and GB is relative to DHW.

Table 2

Renewable energy sources (RES) systems.

\begin{tabular}{|c|c|c|c|c|c|}
\hline $\mathrm{r}, k$ & Equipment & Energy source & Energy produced & Surface $\left[\mathrm{m}^{2}\right]$ & Investment $[€]$ \\
\hline $\mathrm{r}, 1$ & Solar thermal thermosyphon & Solar & Thermal & 1.92 & 1989 \\
\hline $\mathrm{r}, 2$ & Solar thermal forced circulation & Solar & Thermal & 2.02 & 3319 \\
\hline $\mathrm{r}, 3$ & Photovoltaic panel & Solar & Electricity & 11.62 & 12855 \\
\hline
\end{tabular}

Obs.: r, $k$ identifies each RES system. Combinations among RES systems were not considered. The values of the initial investment cost include taxes and fees. 
According to the Energy Certification System (ECS) (DGEG, 2013), the final average for energy used for heating is 61.6 $\left[\mathrm{kWh} / \mathrm{m}^{2}\right]$. This is the result of the seasonal method calculations assuming permanent heating. Establishing a relationship between the two sets of data shows that the final heating energy consumption reported by ICESD represents $13.4 \%$ of the estimated values available in the ECS.

Thus, a consumption reduction factor (occupancy pattern) of 0.134 was applied to be closer to the Portuguese heating habits. For example, in the reference building, the average monthly energy bill just for heating and DHW is $€ 336.40$, considering $100 \%$ of the estimated energy needs by the seasonal method and $€ 86.96$ with the reduction factor (13.4\%).

The energy price trend has been estimated by the EU covering the period up to 2050 (Eurostat-EU Energy, 2013). The energy costs for electricity (€0.2375/kWh) and natural gas (€0.1004/kWh) were obtained from data provided by the Portuguese regulator for energy services (ERSE) (ERSE, 2009). The energy cost for pellets ( $€ 0.0492 / \mathrm{kWh}$ ) was based on current market cost. The primary energy conversion factors considered were $2.5 \mathrm{kWh}$ ep $/ \mathrm{kWh}$ for electricity and $1 \mathrm{~kW} \mathrm{~h} \mathrm{~h}_{\mathrm{ep}} / \mathrm{kW}$ h for gas and pellets, according to Order (extract) D-15793/2013 (extrato, 2013). The primary energy conversion factors considered for RES were $1.0 \mathrm{kWh}$ ep $/ \mathrm{kWh}$, even for electricity produced by photovoltaic panels since it is used only in self-consumption mode.

The economic analysis of conventional systems recommended in ISO 15459 (European Committee for Standardization, 2007) was extended and adapted to the previous selection of RES, insulation options and windows. The solutions were compared with respect to profitability in common cost units, which were euros per kilowatt hour $[€ / \mathrm{kWh}$ ] for equipment (systems) and euro per thermal resistance $[€ / r]$ in the case of insulation and windows (building envelope). Initial investment and maintenance costs were provided by manufacturers associations or obtained through sampling of quotations from the consumer market (CYPE, 2014). For replacement costs, it was considered a lifespan $\left(\tau_{L}\right)$ for every period of: 50 years $\left(\tau_{\mathrm{L}}=50\right)$ for insulation, 40 years $\left(\tau_{\mathrm{L}}=40\right)$ for windows and 20 years $\left(\tau_{L}=20\right)$ for all systems, including RES.

After the useful energy needs for 154,000 packages of measures were obtained, their global cost in the financial perspective described in (EU, 2012) (considering only the return on investment) was calculated. A $6 \%$ nominal discount rate (excluding inflation) was applied to the various costs incurred in an economic lifecycle of 30 years, this being the value currently offered by credit lines especially dedicated to retrofit projects (Buildings Performance Institute Europe, 2013). In addition to the criteria required by (EU, 2012), four indicators were calculated: simple and adjusted payback period, internal rate of return on investment (IRR) and return on investment (ROI).

Following the cost optimality concept, the objective functions $f_{1}$ and $f_{2}$ represent the primary energy needs and global cost, respectively. We consider a multi-objective optimization problem (MOP) in a minimization context. Thus, a MOP is defined as follows (Marler \& Arora, 2004). Let $\mathscr{F}=\left\{f_{1}, f_{2}\right\}, f_{i}: \mathbb{R}^{n} \Rightarrow \mathbb{R}, i=1,2$, the MOP being defined as:

Minimize $: \rightarrow \mathrm{y}=\rightarrow \mathbf{f}(\rightarrow \mathbf{x})=\left[f_{1}(\rightarrow \mathbf{x}), f_{2}(\rightarrow \mathbf{x})\right]$

$\rightarrow \mathbf{x}=\left[x_{1}, \ldots, x_{n}\right] \in \chi \subseteq \mathbb{R}^{n}$

$\rightarrow \mathbf{y}=\left[y_{1}=f_{1}(\rightarrow \mathbf{x}), y_{2}=f_{2}(\rightarrow \mathbf{x})\right] \in \gamma \subseteq \mathbb{R}^{m}$

where, $\rightarrow \mathbf{x}$ is a vector of $\mathbf{n}$ decision variables, while $\rightarrow \mathbf{y}$ represents a 2-dimensional objective vector mapping solutions $\rightarrow \mathbf{x} \in \chi$ into the objective function space $\gamma$. The objective functions are defined by Eqs. (4) and (5).

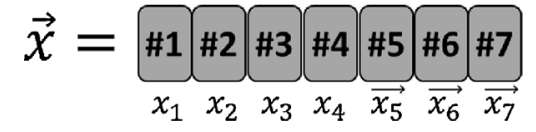

Fig. 1. Representation of the decision variables.

Each component of the $\rightarrow \mathbf{x}$ vector corresponds to a decision variable, i.e., specifies the cost and corresponding technical characteristics linked to each retrofit option. Thus, for roof(\#1), walls (\#2), ground floor (\#3) and windows (\#4), the technical characteristic is thermal transmittance value $U$. For heating (\#5) and DHW (\#6), the technical characteristic is efficiency and for RES (\#7) is energy production. Fig. 1 shows the solution representation (encoding), where each vector position has a set of possible valid values:

\subsubsection{Primary energy needs}

In this study, the cooling needs were not considered. According to the Portuguese legislation, it is allowed to neglect the cooling needs once the risk of overheating is minimal. Thus, the total primary energy needs, PE, result from the sum of the heating energy needs, $E_{\mathrm{h}, \mathrm{k}}$, and domestic hot water production, $E_{\mathrm{w}, \mathrm{k}}$, less any contributions from renewable energy sources per $\mathrm{m}^{2}$ of floor area, $E_{\mathrm{r}, \mathrm{k}}$ (adapted from (REH, 2013)):

$$
\begin{aligned}
f_{1}(\rightarrow x)=\operatorname{PE}(\rightarrow x)=\left[\sum_{k=0}^{K_{h}} \frac{f_{\mathrm{h}, \mathrm{k}}\left(x_{5}\right) E_{\mathrm{h}, \mathrm{k}}\left(x_{5}\right)}{\eta_{\mathrm{h}, \mathrm{k}}\left(x_{5}\right)} P_{\mathrm{h}, \mathrm{k}}\left(x_{5}\right)\right] \\
+\left[\sum_{k=0}^{K_{w}} \frac{f_{w, k}\left(x_{6}\right) E_{\mathrm{w}, \mathrm{k}}\left(x_{6}\right)}{\eta_{\mathrm{w}, \mathrm{k}}\left(x_{6}\right)} P_{\mathrm{w}, \mathrm{k}}\left(x_{6}\right)\right]-\left[\sum_{k=0}^{K_{r}} E_{\mathrm{r}, \mathrm{k}}\left(x_{7}\right) P_{\mathrm{r}, \mathrm{k}}\left(x_{7}\right)\right]
\end{aligned}
$$

where, a given system $k$ is linked to a single energy source; $K_{\mathrm{h}}$, $K_{\mathrm{w}}$ and $K_{\mathrm{r}}$ are the number of systems for space heating, DHW and renewable energy production, respectively; $f_{\mathrm{h}, \mathrm{k}}$ and $f_{\mathrm{w}, \mathrm{k}}$ are the percentage of the energy needs provided by each system $k ; P_{\mathrm{h}, \mathrm{k}}, P_{\mathrm{w}, \mathrm{k}}$ and $P_{r, k}$ are the conversion factor between final energy and primary energy of each system $\mathrm{k} ; \eta_{h, k}$ and $\eta_{w, k}$ are the efficiency of each system and $x_{5}$ to $x_{7}$ are the associated decision variables, because these variables have a direct effect on the two objective functions, while the variables $x_{1}$ to $x_{4}$ affect the useful energy needs and, indirectly, the objective functions (see Fig. 1).

The useful energy needs of the building, $E_{\mathrm{h}, \mathrm{k}}$ and $E_{\mathrm{w}, \mathrm{k}}$, are input data to the genetic algorithm and were previously calculated by a software developed for this purpose, which follows the standard seasonal method proposed in EN ISO 13790:2008 (European, 2008) together with specific rules defined in the Portuguese legislation (REH, 2013). This calculation uses the decision variables $x_{1}$ to $x_{4}$ to obtain $E_{\mathrm{h}, \mathrm{k}}$, since the useful energy needs also depend on the insulation thicknesses and windows, among other factors.

The current Portuguese legislation determines that the minimum energy requirements for existing buildings undergoing major interventions should be established based on reference parameters of thermal and energy efficiency applied to the envelope and equipment of the building. In case of existing buildings constructed before 1960 it is accepted that the value of PE can exceed up to 50\% the regulatory limit set for new buildings.

\subsubsection{Global cost}

The global cost, $\mathrm{GC}(\rightarrow x, \tau)$ for set of measures $J$ (where, $j=0$ corresponds to the BAU scenario), referring to starting year, $i=0$, over the planning period $\tau$, results from the sum of the full investment costs, $\mathrm{IC}_{i, j}$, and the energy costs, $\mathrm{EC}_{i, j}$, during year $i$, affected 
by the discount factor, $D_{i}$. In this study a period $\tau=30$ years was considered:

$f_{2}=\mathrm{GC}(\rightarrow x, \tau)=\sum_{j=0}^{J}\left[\sum_{i=0}^{\tau} \mathrm{IC}_{i, j}(\rightarrow x)+\mathrm{EC}_{i, j}(\rightarrow x)\right] D_{i}$

The discount factor for year $i, D_{i}$, is based on the real discount rate $R$ to be calculated as:

$D_{i}=\left(\frac{1}{1+R / 100}\right)^{i}$

The investment costs, $\mathrm{IC}_{i, j}$, result from a broad concept of full investment cost and are obtained from the sum of the initial investment, $I_{i, j}$, the maintenance costs, $M_{i, j}$, the replacement costs, $R_{i, j}$, less the residual value, $V_{i j}$ :

$\mathrm{IC}_{i, j}(\vec{x})=\left(I_{i, j}+M_{i, j}+\delta_{i \tau_{L}} R_{i, j}-\delta_{i \tau} V_{i, j}\right)$

where, $\delta_{n m}$ is the Kronecker delta symbol to be calculated as:

$\delta_{n m}= \begin{cases}0, & \text { if } n \neq m \\ 1, & \text { if } n=m\end{cases}$

The replacement costs, $R_{i, j}$, associated with each set of measures are added just at the end of the respective lifespan $\tau_{\mathrm{L}}$. Similarly, the residual value, $V_{i, j}$, is subtracted just at the end of the calculation period $\tau$.

In the case under study, the investment costs, $\mathrm{IC}_{i, j}$, result from the sum of the measures obtained by changing 4 elements (insulation, windows, conventional systems and renewable energy systems), identified by the subscripts ins, win, sys and res, respectively:

$I_{i, j}(\rightarrow x)=\left(I_{\mathrm{ins}, i}+I_{\mathrm{win}, i}+I_{\mathrm{sys}, i}+I_{\mathrm{res}, i}\right)$

In turn, ins (insulation) results from the sum of the 3 envelope elements that are changed, identified by the subscripts insroof, inswalls and insfloor, denoting roof, walls and ground floor, respectively:

$I_{\text {ins }, i}(\rightarrow x)=\left(I_{\text {insroof }, i}+I_{\text {inswalls }, i}+I_{\text {insfloor }, i}\right)$

Similarly, sys (systems) and res (renewable energy systems) result from the sum of the systems that are changed, identified by the subscripts $h, w$, and $r$ (see Tables 1 and 2), respectively for heating, DHW and RES:

$I_{\mathrm{sys}, i}(\rightarrow x)=\sum_{k=1}^{4}\left(I_{\mathrm{h}, i, \mathrm{k}}+I_{\mathrm{w}, i, \mathrm{k}}\right), \quad I_{\mathrm{res}, i}(\rightarrow x)=\sum_{k=1}^{3} I_{\mathrm{r}, i, \mathrm{k}}$

The same procedure is applied to the other parameters $M_{i, j}, R_{i, j}$ and $V_{i, j}$.

The energy costs, $\mathrm{EC}_{i, j}$, result from the sum of the energy costs for heating, $\mathrm{EC}_{\mathrm{h}, i}$, and the energy costs for $\mathrm{DWH}, \mathrm{EC}_{\mathrm{w}, i}$ :

$\mathrm{EC}_{i, j}(\rightarrow x)=\left(\mathrm{EC}_{\mathrm{h}, i}+\mathrm{EC}_{\mathrm{w}, i}\right)$

The energy costs for heating and $\mathrm{DHW}, \mathrm{EC}_{\mathrm{h}, i}$ and $\mathrm{EC}_{\mathrm{w}, i}$, result from the final energy, $\mathrm{FE}_{\mathrm{h}, i}$ and $\mathrm{FE}_{\mathrm{w}, i}$, respectively, multiplied by the cost for the corresponding source of energy used by each system, $C_{\mathrm{ele}, i}, C_{\mathrm{gas}, i}$ and $C_{\mathrm{pel}, i}$ (electricity, gas and pellets), in a given year $i$, for heating

$\mathrm{EC}_{\mathrm{i}, h}=\left\{\begin{array}{l}\mathrm{FE}_{\mathrm{h}, i} \delta_{\mathrm{k} 1} C_{\mathrm{ele}, i} \\ \mathrm{FE}_{\mathrm{h}, i} \delta_{\mathrm{k} 2} C_{\mathrm{ele}, i} \\ \mathrm{FE}_{\mathrm{h}, i} \delta_{\mathrm{k} 3} C_{\mathrm{pel}, i} \\ \mathrm{FE}_{\mathrm{h}, i} \delta_{\mathrm{k} 4} C_{\mathrm{gas}, i}\end{array}\right.$ and for DHW

$\mathrm{EC}_{i, \mathrm{w}}=\left\{\begin{array}{l}\mathrm{FE}_{\mathrm{w}, i} \delta_{\mathrm{k} 1} C_{\mathrm{gas}, i} \\ \mathrm{FE}_{\mathrm{w}, i} \delta_{\mathrm{k} 2} C_{\mathrm{gas}, i} \\ \mathrm{FE}_{\mathrm{w}, i} \delta_{\mathrm{k} 3} C_{\mathrm{pel}, i} \\ \mathrm{FE}_{\mathrm{w}, i} \delta_{\mathrm{k} 4} C_{\mathrm{gas}, i}\end{array}\right.$

The net final energy needs after contributions from RES, $\mathrm{FE}_{\mathrm{h}, \mathrm{k}}$ and $\mathrm{FE}_{\mathrm{w}, \mathrm{k}}$, are obtained assuming the selected heating and DHW systems (Table 1) and RES systems (Table 2). Considering particularities on the relation between conventional and RES systems, $\mathrm{FE}_{\mathrm{h}, \mathrm{k}}$ and $\mathrm{FE}_{\mathrm{w}, \mathrm{k}}$ are calculated as follows:

$\mathrm{FE}_{\mathrm{h}, \mathrm{k}}=\frac{f_{\mathrm{h}, \mathrm{k}} E_{\mathrm{h}, \mathrm{k}}}{\eta_{\mathrm{h}, \mathrm{k}}}-\delta_{\mathrm{k} 3} E_{\mathrm{r}, \mathrm{k}}$

$\mathrm{FE}_{\mathrm{w}, \mathrm{k}}=\frac{\left(f_{\mathrm{w}, \mathrm{k}} E_{\mathrm{w}, \mathrm{k}}\right)-\delta_{\mathrm{k} 1} E_{\mathrm{r}, \mathrm{k}}-\delta_{\mathrm{k} 2} E_{\mathrm{r}, \mathrm{k}}}{\eta_{\mathrm{w}, \mathrm{k}}}$

The costs of energy, $C_{\mathrm{ele}, i}, C_{\mathrm{gas}, i}$ and $C_{\mathrm{pel}, i}$, are affected by a factor for readjustment $f C_{\text {ele, } i}$ (being the same for gas and pellets)

$C_{\text {ele }, i}=\left\{\begin{array}{cc}C_{\text {ele }, i}, & i=1 \\ C_{\text {ele }, i} f C_{\text {ele }, i}, & 1<i \leq 30\end{array}\right.$

According to the following indices based on the European Commission's estimates for energy prices development in the next 30 years (Eurostat-EU Energy, 2013):

$f C_{\mathrm{ele}, i}= \begin{cases}1.0349, & i<5 \\ 1.0000, & 5 \leq i<10 \\ 1.0040, & 10 \leq i<15 \\ 1.0000, & 15 \leq i<20 \\ -1.0058, & 20 \leq i<25 \\ -1.0020, & 25 \leq i \leq 30\end{cases}$

\subsection{A multi-objective approach}

The case study has variants with RES systems embedded in it, in a total of 154,000 possible combinations (packages). This number of combinations can increase significantly with the addition of new types of components or when the number of systems increases. Due to the large number of possible combinations for the problem under study, we used a multi-objective genetic algorithm (MOGA) specially developed to find non-dominated packages (solutions). A non-dominated package is a feasible solution for which no other feasible package exists simultaneously improving all objective functions, i.e. the improvement of an objective function value can only be achieved by accepting to degrade at least another objective function. That is, non-dominated packages entail a trade-off between the competing objectives in order to select a compromise solution. The algorithm proposed was called Genetic Algorithm for Energy Efficiency in Buildings (GAEEB) and its pseudo-code is presented in Algorithm 1. The GAEEB is based on NSGA-II (Deb, Pratap, Agarwal, \& Meyarivan, 2002), which has been used to solve combinatorial problems in several areas as building retrofit (Asadi et al., 2014), optimal placement and sizing of distributed generation (Wanxing, Ke-yan, Yuan, Xiaoli, \& Yunhua, 2015) and generation expansion planning (Kannan, Baskar, McCalley, \& Murugan, 2009), among many others.

GAEEB creates a population consisting in set of packages. Each package corresponds to a random combination of the decision variables. Packages are then evaluated. The stopping criterion is the number of evaluations of objective functions. The $n$ package population evolves using selection, crossover and mutation operators. The selection procedure consists in a binary tournament 


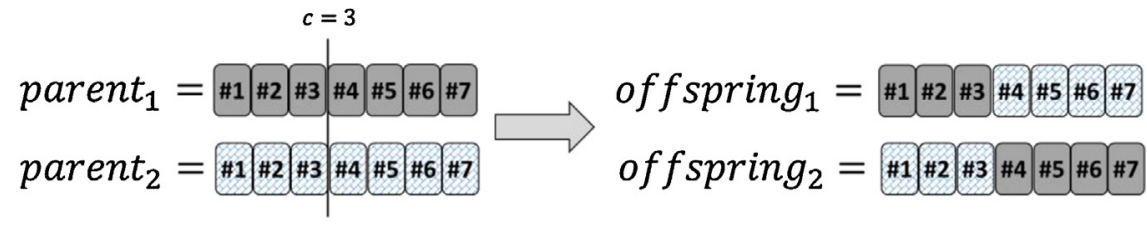

Fig. 2. Illustration of the crossover operator.

scheme (Coello, Lamont, \& Veldhuizen, 2007). Crossover and mutation operators were especially designed for the problem of building retrofit. A new population with $2 \times n$ packages is created by joining the packages of the pop and popOffspring populations.

Algorithm 1 - Genetic Algorithm for Energy Efficiency in Buildings (GAEEB).

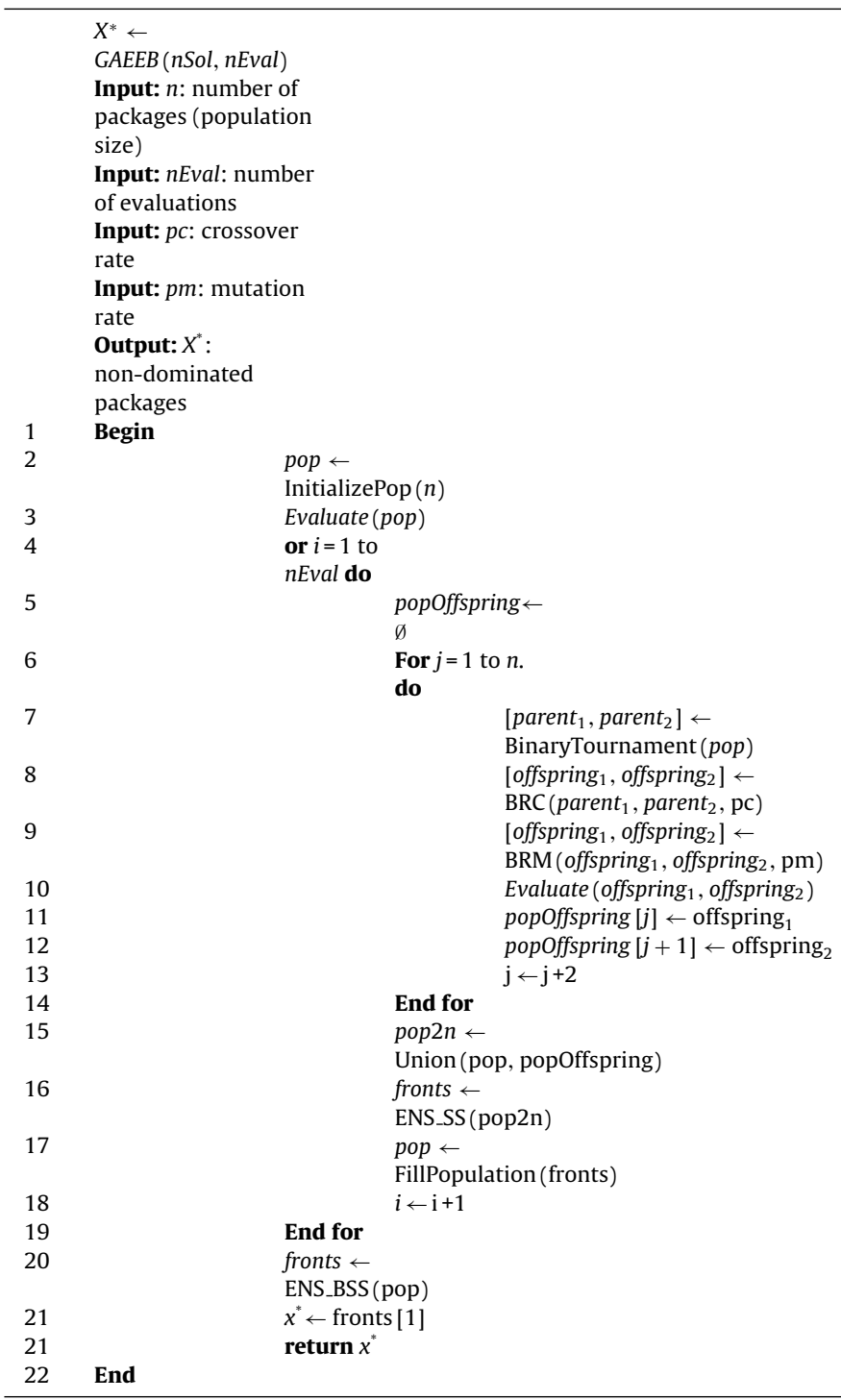

GAEEB is an elitist algorithm, where the best packages found are preserved using a procedure known as Efficient Non-dominated Sort with Sequential Search Strategy (ENS-SS) (Xingyi, Ye, Ran, \& Yaochu, 2015). The function FillPopulation (.) creates a new population using the non-dominated fronts generated by ENS-SS. When packages of a front exceed the size of the population, a crowding distance (Deb et al., 2002) procedure is used to preserve diversity and obtain a well-distributed non-dominated front (line 17).
The crossover operator - Building Retrofit Crossover, BRC(.) - has been specially designed to create new packages. The BRC operator produces a pair of offspring packages from a pair of parent packages selected from the current population. The crossover operator has probability pc and uses one cut-off point (Fig. 2). In this case, the cut-off point $c$ is chosen at random, where, $1<c<7$. The example shows two packages ( parent $_{1}$ and parent $_{2}$ ) selected by binary tournament $(c=3)$. The operator creates two packages (offspring $_{1}$ and offspring ${ }_{2}$ ) that are composed of parts of parent 1 and parent 2 .

The mutation operator is a "flip mutation" (Coello et al., 2007). In this Building Retrofit Mutation-BRM(.), each package element has a probability pm of experiencing change. This operator is applied to packages resulting from the crossover operator. The new values for each randomly selected element to be altered are obtained from the set of feasible alternatives. This ensures that the new generated packages are feasible.

\section{Results}

These results were divided for better understanding. First, the results from GAEEB are presented and discussed in Section 4.1. After, results of cost-optimal levels (Section 4.2) and a return on investment approach (Section 4.3) are shown and analysed.

\subsection{Results of GAEEB}

The purpose of this section is to evaluate the results of GAEEB, which was described in section 3.2. The "brute-force" algorithm was implemented to create all possible packages for the problem, totalling 154,000 combinations. The non-dominated packages were identified using the Efficient Non-dominated Sort with Sequential Search Strategy (Xingyi et al., 2015). The solution proposed by GAEEB was able to generate the optimal cost curve accurately with a significant reduction of processing time.

All the runs considered the following set of parameters: population size $(n)=70$; number of evaluations ( $n$ Eval $=[500,750$, $\ldots, 3000$ ] with step 250; crossover rate $(p c)=0.9$; and mutation rate $(\mathrm{pm})=0.04$. The experiments involved 33 runs of the GAEEB, using a PC Intel Core I7-3632, 2.2 GHz CPU with 8GB of RAM.

The quality of the results provided by GAEEB was assessed using the hypervolume quality indicator $(H)$ (Beume, Fonseca, LoípezIbáñez, Paquete, \& Vahrenhold, 2009; Zitzler \& Thiele, 1998), which is a measure of the space dominated by a set of non-dominated points that are bounded by a dominated point called reference $\left(P_{\text {ref }}\right)$. To compute the hypervolume value, a solution $\rightarrow \boldsymbol{x}_{\boldsymbol{i}}$ in the non-dominated frontier $\left(\mathrm{PF}_{\text {known }}\right)$ for a 2-dimensional MOP defines a rectangle area, $c\left(\rightarrow \boldsymbol{x}_{\boldsymbol{i}}\right)$, bounded by an origin and $f\left(\rightarrow \boldsymbol{x}_{\boldsymbol{i}}\right)$. The union of such rectangle areas is called hyperarea of $\mathrm{PF}_{\mathrm{known}}$ :

$H\left(\mathrm{PF}_{\text {known }}\right)=\bigcup_{i} c\left(\rightarrow \boldsymbol{x}_{\boldsymbol{i}}\right) \mid \forall \rightarrow \boldsymbol{x}_{\boldsymbol{i}} \in \mathrm{PF}_{\text {known }}$

It is assumed that the reference point $\left(P_{\text {ref }}\right)$ for assessing the hypervolume is the worst value for each objective in the non-dominated region plus $10 \%$. The union of areas 


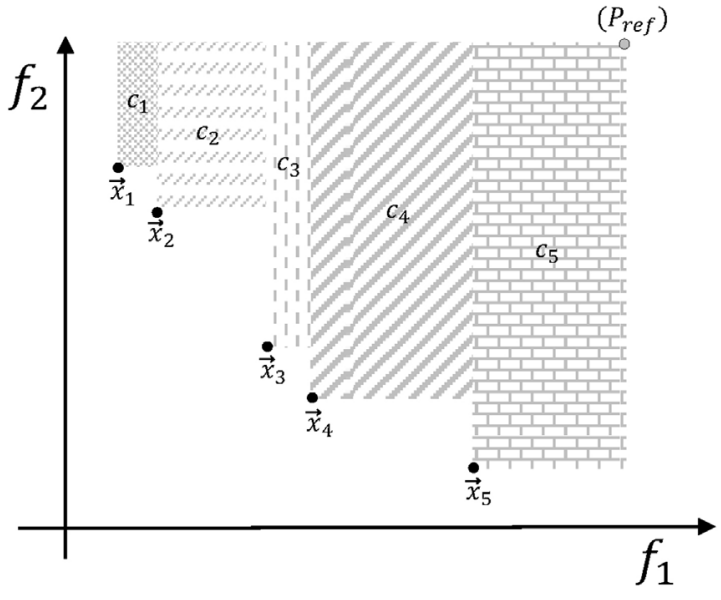

Fig. 3. The value of the hypervolume indicator is the (hyper)volume of the region consisting of the points that dominate a reference point $P_{\text {ref. }}$.

$\left\{c_{1}, c_{2}, \ldots, c_{5}\right\}$ highlighted in Fig. 3 corresponds to hypervolume of $P F_{\text {known }}\left\{\rightarrow x_{1}, \rightarrow x_{2}, \ldots, \rightarrow x_{5}\right\}$ considering the reference point $P_{\text {ref. }}$.

Fig. 4 shows the hypervolume values calculated for 33 runs of the algorithm for each $n$ Eval defined. GAEEB converges to the hypervolume with only 3000 evaluations of the objective functions. The black dots represent the hypervolume obtained by non-dominated packages after evaluation using the "brute force" assessment of 154,000 packages. The non-dominated packages found thereafter compose the optimal Pareto frontier.

Table 3 shows the hypervolume values after 33 runs of the algorithm. The GAP column shows the percentage deviation from the average obtained in relation to hypervolume of the non-dominated solutions. Note that after 2000 evaluations of the objective functions the algorithm has a similar behavior and converges for hypervolume values with GAP below $1.5 \%$.

Fig. 5 presents the non-dominated solutions (packages) found by GAEEB in a single run. GAEEB was able to find a large number of optimum packages (solutions) for the problem under study. Of the 27 optimal packages, i.e., non-dominated packages known to the problem, the GAEEB algorithm found an average of 25.3 optimal packages at 3000 evaluations. In addition, it should be noted that the algorithm requires a very low computation time. GAEEB did 500 evaluations in 84 milliseconds (Intel ${ }^{\circledR}$ Core i5 desktop with
Table 3

Hypervolume values obtained by 33 rounds of GAEEB for the number of objective function evaluations

\begin{tabular}{lllllr}
\hline \multirow{2}{*}{$\begin{array}{l}\text { Number of } \\
\text { evaluations }\end{array}$} & \multicolumn{2}{l}{ Hypervolume values } & & Dev. std. & GAP (\%) \\
\cline { 2 - 4 } & Best & Worst & Average & & \\
\hline 500 & 0.6961 & 0.5237 & 0.6075 & 0.0483 & 15.75 \\
750 & 0.7199 & 0.5285 & 0.6484 & 0.0448 & 10.08 \\
1000 & 0.7205 & 0.6032 & 0.6797 & 0.0358 & 5.76 \\
1250 & 0.7207 & 0.6511 & 0.6982 & 0.0196 & 3.19 \\
1500 & 0.7207 & 0.6572 & 0.7045 & 0.0196 & 2.32 \\
1750 & 0.7208 & 0.6726 & 0.7091 & 0.0137 & 1.68 \\
2000 & 0.7207 & 0.6767 & 0.7120 & 0.0106 & 1.28 \\
2250 & 0.7208 & 0.6690 & 0.7118 & 0.0141 & 1.31 \\
2500 & 0.7208 & 0.6723 & 0.7134 & 0.0152 & 1.08 \\
2750 & 0.7209 & 0.6722 & 0.7106 & 0.0138 & 1.47 \\
3000 & 0.7209 & 0.6721 & 0.7111 & 0.0154 & 1.40 \\
\hline
\end{tabular}

$3.30 \mathrm{GHz}$ ), while only 313 milliseconds were needed to calculate 3000 combinations.

In the negative quadrant, we find the packages that incorporate photovoltaic panels. They produce more energy than what is consumed within the scope of this study (heating of living area and domestic hot water). Table 4 shows 4 selected non-dominated packages found by GAEEB, including values of thermal transmittance value $U$ for roof (\#1), walls (\#2), ground floor (\#3) and windows (\#4) and values for heating (\#5), DHW (\#6) and RES (\#7), as well the results of the primary energy needs and global cost, $f_{1}$ and $f_{2}$, respectively.

\subsection{Cost-optimal results}

The cost-optimal curve behaviour was analysed according to the methodological framework proposed in Delegated Regulation 244. As already explained in 3.1, the primary energy results for the cost optimality assessment were calculated using the seasonal steadystate method with a reduction factor of 0.134 . The cost-optimal levels in the financial perspective (FIN =6\%) are presented in Fig. 6 . The results show the cost-optimal curves for each combination of insulation, windows and the use of different heating and DHW systems, plus options for RES. The plot presents the distribution of solutions, and it is possible to see groups of packages linked to certain conventional heating systems (electric heater-EH, air conditioner-AC, gas boiler-GB and biomass boiler-BM).

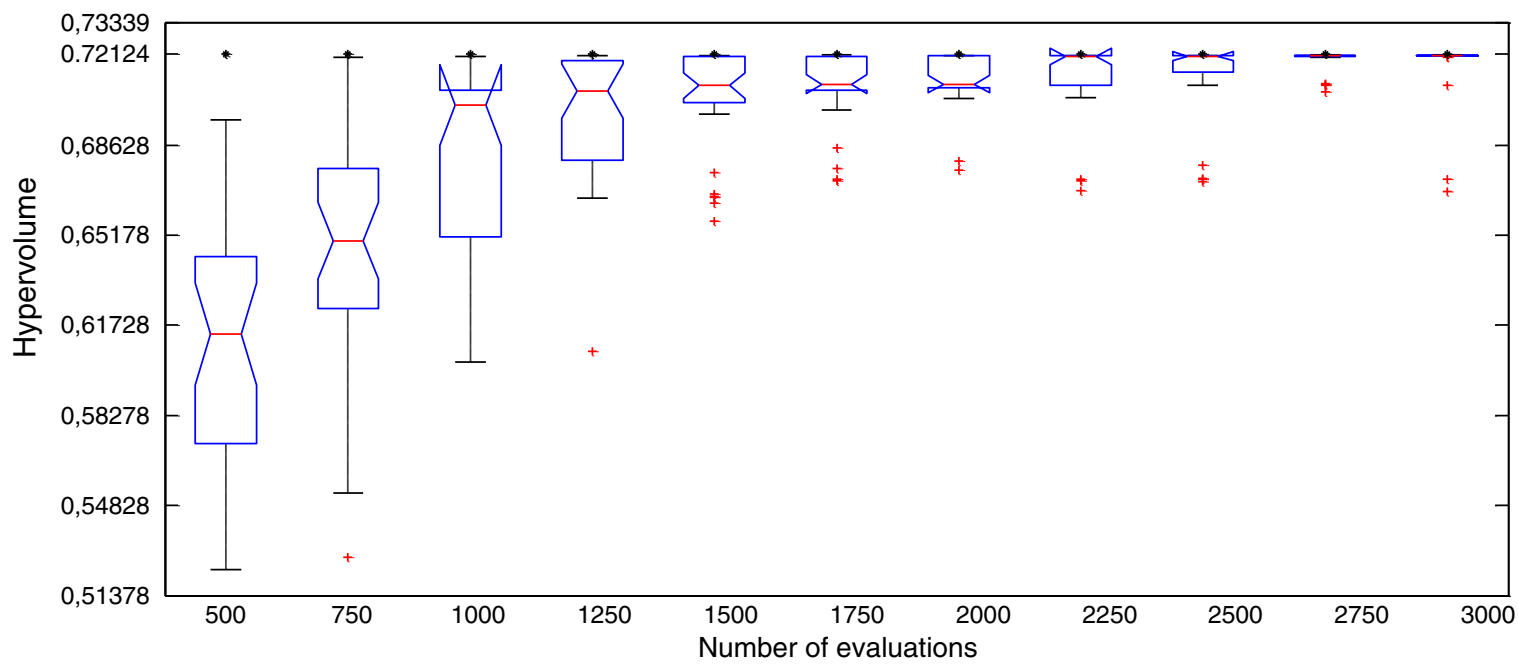

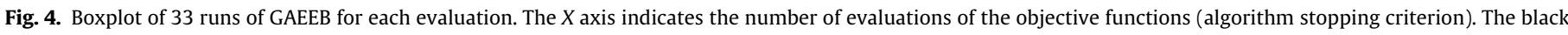
points represent the hypervolume calculated for the Pareto front (optimal points). 


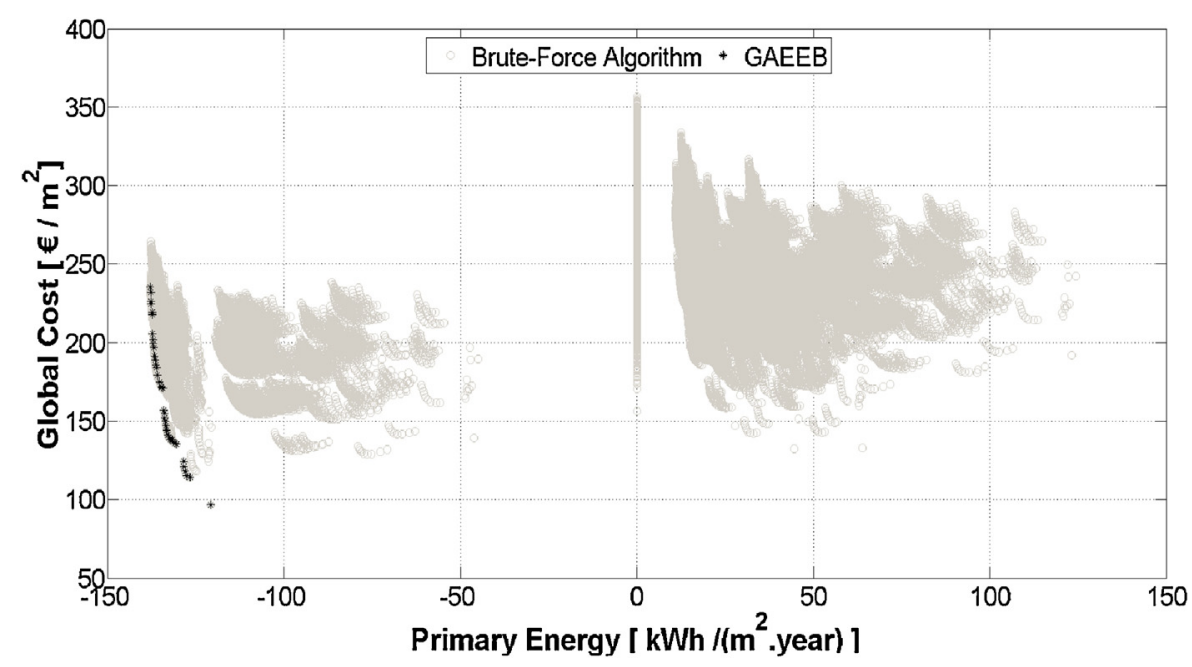

Fig. 5. Non-dominated packages (solutions) found in a run of GAEEB. In light gray, the search space of the problem created by a "brute force" algorithm is displayed.

Table 4

Selected non-dominated packages found by GAEEB.

\begin{tabular}{|c|c|c|c|c|c|c|c|c|}
\hline $\begin{array}{l}\text { Roof }(\# 1) \\
{\left[\mathrm{W} /\left(\mathrm{m}^{2} . \mathrm{C}^{\circ}\right)\right]}\end{array}$ & $\begin{array}{l}\text { Walls }(\# 2) \\
{\left[\mathrm{W} /\left(\mathrm{m}^{2}{ }^{\circ} \mathrm{C}\right)\right]}\end{array}$ & $\begin{array}{l}\text { Floor }(\# 3) \\
{\left[\mathrm{W} /\left(\mathrm{m}^{2}{ }^{\circ} \mathrm{C}\right)\right]}\end{array}$ & $\begin{array}{l}\text { Windows }(\# 4) \\
{\left[\mathrm{W} /\left(\mathrm{m}^{2}{ }^{\circ} \mathrm{C}\right)\right]}\end{array}$ & DHW (\#5) & Heating (\#6) & RES (\#7) & $f_{1}\left[\mathrm{kWh} /\left(\mathrm{m}^{2} \mathrm{y}\right)\right]$ & $f_{2}\left[€ / \mathrm{m}^{2}\right]$ \\
\hline $2.800^{\mathrm{a}}$ & 2.000 & 1.650 & 5.1 & GWH 0.78 & AC & PV & -121 & 97 \\
\hline 0.494 & 0.462 & 1.650 & 5.1 & GWH 0.78 & $A C$ & PV & -132 & 138 \\
\hline 0.208 & 0.462 & 1.650 & 5.1 & GWH 0.78 & AC & PV & -135 & 178 \\
\hline $0.187^{b}$ & 0.182 & 0.182 & 1.87 & GWH 0.78 & AC & PV & -138 & 235 \\
\hline
\end{tabular}

a It corresponds to package 13 , in Table 5.

b It corresponds to package 12, in Table 5.

As stated above, in the negative quadrant, for example, two of that clouds are groups of packages that incorporate photovoltaic panel-PV, linked to two different conventional systems: air conditioner (cloud on the left) and electric heater (on the right). The values become negative because the photovoltaic panel produces more energy than consumed in the scope of this study (heating of living area and domestic hot water), being the energy surplus fully tapped by other applications (lighting, appliances etc.). All packages that include biomass boiler, BM, appear concentrated and pointing to zero-primary energy needs since the total energy needs are supplied by RES. Both solar thermal systems, thermosyphon-ST $\mathrm{T}$ and forced circulation-ST C, reduce primary energy needs, as it is expected from RES systems, but the solution of thermosyphon has the advantage of reducing the global cost, except in combination with biomass $(\mathrm{BM}+\mathrm{STT})$, this system using the lower cost fuel (pellets). The vertical lines show energy limits defined as national requirements that depend on the heating system type (AC-orange, GB-blue and EH-gray).

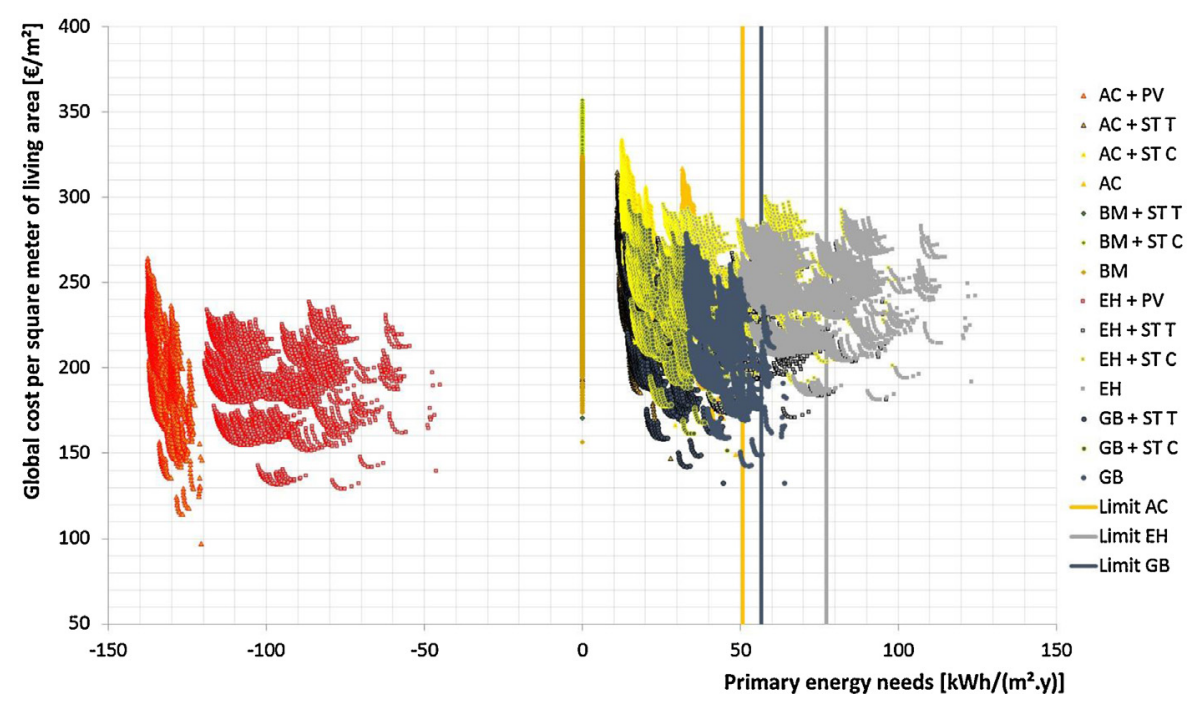

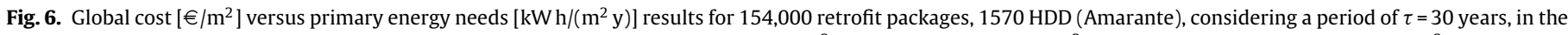
financial perspective (FIN =6\%). The national PE requirements (limits) are $50.87\left[\mathrm{kWh} /\left(\mathrm{m}^{2} \mathrm{y}\right)\right]$ for $\mathrm{AC}, 56.72\left[\mathrm{kWh} /\left(\mathrm{m}^{2} \mathrm{y}\right)\right]$ for GB and BM and $77.23\left[\mathrm{~kW} \mathrm{~h} /\left(\mathrm{m}^{2} \mathrm{y}\right)\right]$ for EH 


\subsection{Return on investment approach}

In order to determine the advantages of investment in energy retrofit for investors, regarding return on investment analysis, function $f_{1}$ is replaced by the adjusted value of additional investment, $f_{3}$, which consists in the total amount invested in energy efficiency measures beyond the BAU scenario. The additional investment, $\mathrm{AI}(\tau)$, referring to starting year, $i=0$, over the calculation period $\tau$, results from the full investment costs, $\mathrm{IC}_{i, j}$, during year $i$, for measure or set of measures $j$, less $\mathrm{IC}_{\mathrm{BAU}, i, 0}$, which represents the corresponding values for the BAU scenario. These values are discounted referring to the initial year, $i=0$, according a discount factor
$D_{i}$. For calculation in the financial perspective having a period $\tau=30$ years:

$f_{3}=\mathrm{AI}(\tau)=\sum_{j=1}^{J}\left[\sum_{i=0}^{\tau} \mathrm{IC}_{i, j} D_{i}\right]-\left[\sum_{i=0}^{\tau} \mathrm{IC}_{\mathrm{BAU}, i, 0} D_{i}\right]$

The investor's point of view is considered the situation changes significantly, as shown in Fig. 7. Packages that include photovoltaic panel, which would be considered best options according to the cost-optimal approach, are not acceptable according to return on investment approach due to the high initial investment required. Since the discount rate is significantly higher than the estimates of

a)

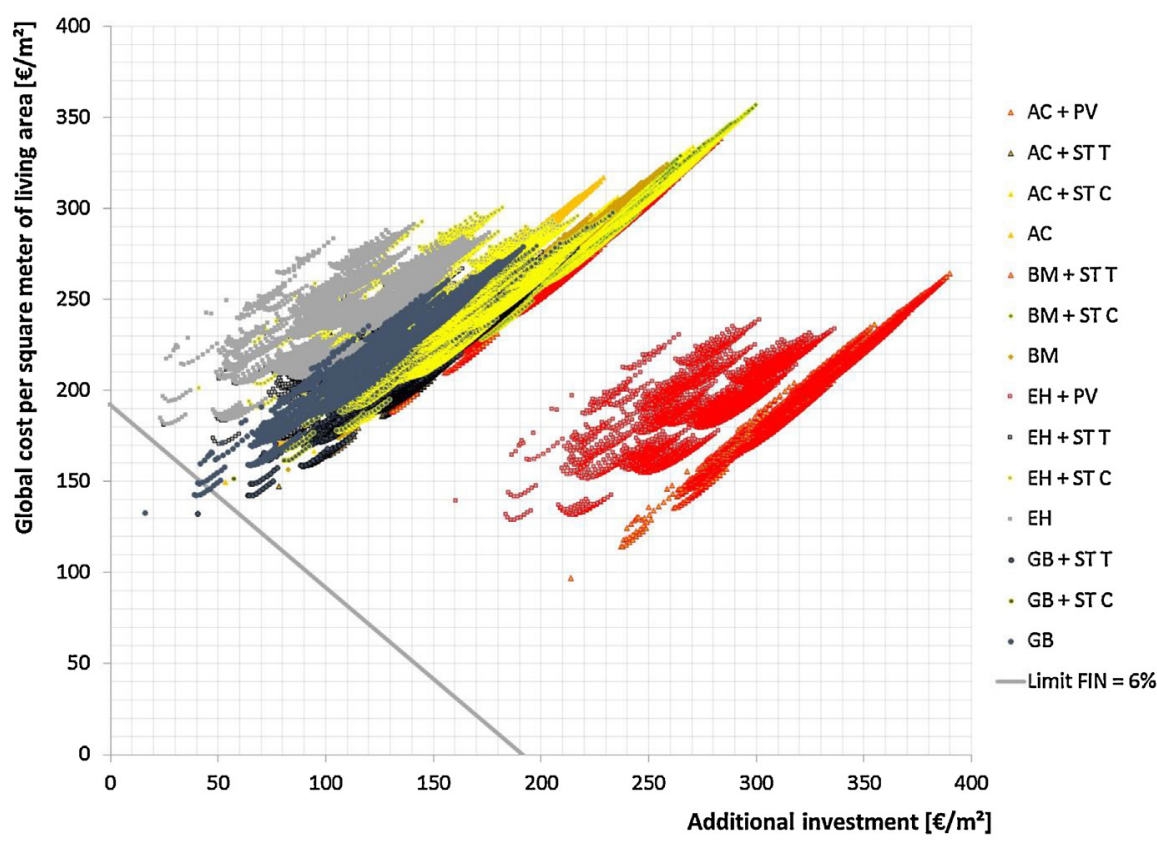

b)

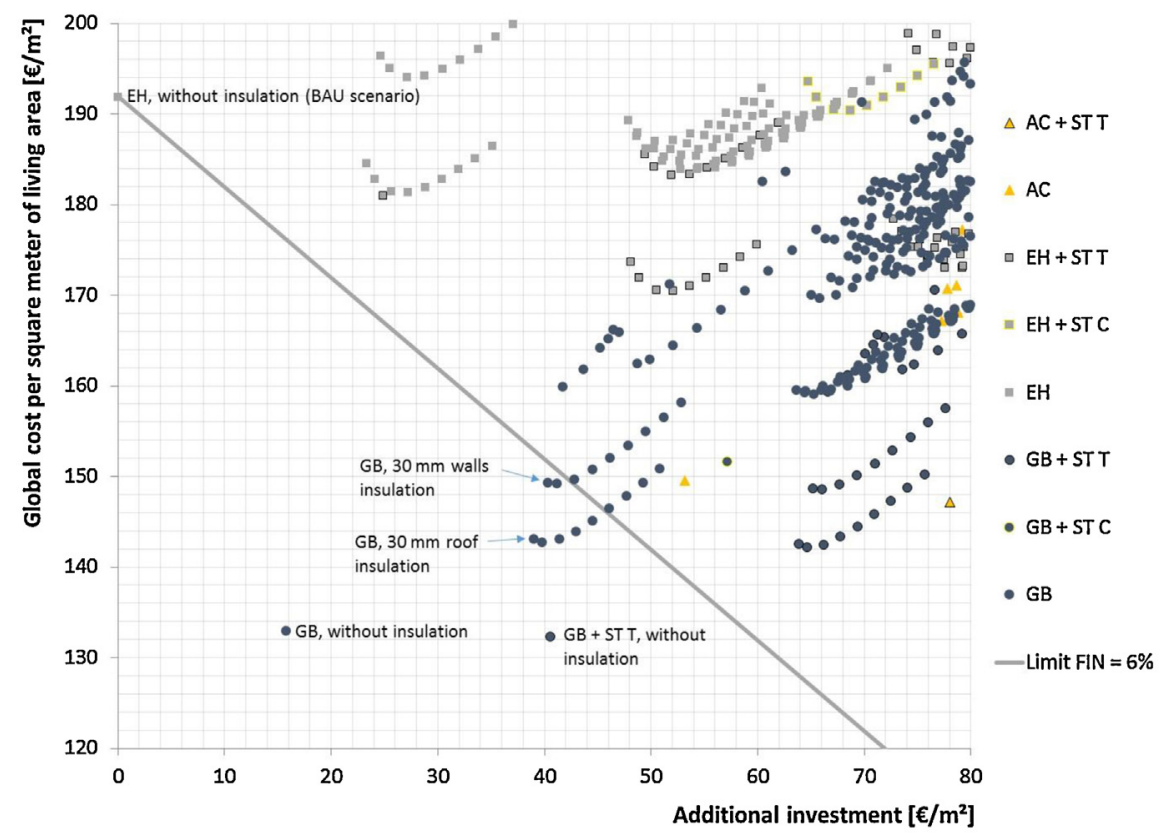

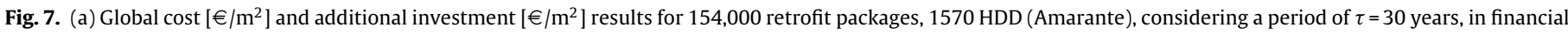
perspective (FIN =6\%); (b) Zoom in range. 
the evolution of energy prices suggested by Eurostat (Eurostat-EU Energy, 2013), the potential energy cost savings become insufficient to offset the initial investment.

Fig. 7 includes a grey line where the global cost of a given package, plus the additional investment (amount invested beyond the BAU scenario), is equal to the global cost of the BAU scenario plus costs for maintenance, replacement and residual value of windows and systems already present in the reference building, during the period of $\tau=30$ years.

As the global cost and the additional investment are shown in net present value, packages can be compared using this gray line as reference. Only solutions that are within the triangle formed by this line and the axes deliver positive ROI and the additional investment is not higher than the global cost in BAU scenario, when considering a discount rate of $6 \%$. In packages that are on this line, the additional investment does not offset the relative decrease in global cost, when compared with the BAU scenario. The remaining solutions (outside the triangle) can even reduce the global cost (when below $€ 191.89$ ), but the ROI is negative.

In this type of analysis, the discount rate of $6 \%$ can also be understood as cost of capital, especially when the investor does not have the resources and needs to have access to credit lines to make additional investment, in comparison with the BAU scenario. This analysis is limited to the return on investment for packages that provide the same conditions of thermal comfort, not considering other benefits that certain energy retrofit measures can provide. Concerning this issue, the interest of each investor must be considered in the election of the package with higher added value, among those with higher return than the BAU scenario, as well as the minimum requirements at national level. For example, we can see that GB without insulation is the best package from the investor's point of view but this option does not meet the minimum requirements, as shown in Fig. 8. After installing ST T, the option GB (still without insulation) meets the minimum national requirements.
The replacement of the DHW system presents an opportunity for exchange at the end of the existing equipment's life cycle. When considering insulation, the best option is the thickness of $30 \mathrm{~mm}$, only in the roof. In this reference building, roof insulation is more cost effective than in the other elements, followed by insulation in the walls. The insulation of the ground floor is the least cost effective due to their high costs because increased difficulties for adoption of this measure in existing buildings. In general, in this reference building as in others, the investment in insulation becomes more cost-effective when useful energy needs are higher or the heating system is a low efficiency one.

The analysis of 18 selected packages of efficiency measures in comparison with the reference scenario shown in Table 5 enables us to understand the impact of each action, alone and in combination. Package 0 represents the reference building in a BAU scenario. The elements that are changed in comparison with the BAU scenario are in yellow. The values that do not meet minimum requirements on primary energy needs, global cost or ROI are in orange, within their respective columns. Similarly, the blue values represent the best within these same columns. Note that package 12 has the lowest need for primary energy, package 13 has the lowest global cost, and package 14 has the highest ROI (taking in account minimum requirements for primary energy) of all 154,000 combinations. Packages 1-4 consist of just the insulation of components, EPS boards with a thickness of 60 or $80 \mathrm{~mm}$. In Package 5 only the windows are replaced. Packages 6-11 consist of replacing systems or installation of RES systems. That is, packages 1-11 represent individual measures, highlighted, and their impact on the primary energy needs, global cost and ROI. Packages 12-18 represent combined measures and it is possible to see the interaction between them. The comparison of these packages confirms that replacement of the heating system is far more cost effective than the improvement of insulation in the opaque envelope, according to the economic criterion ROI. While package 14 is the best option, package 12 occupies the 26123st position in the ROI ranking.

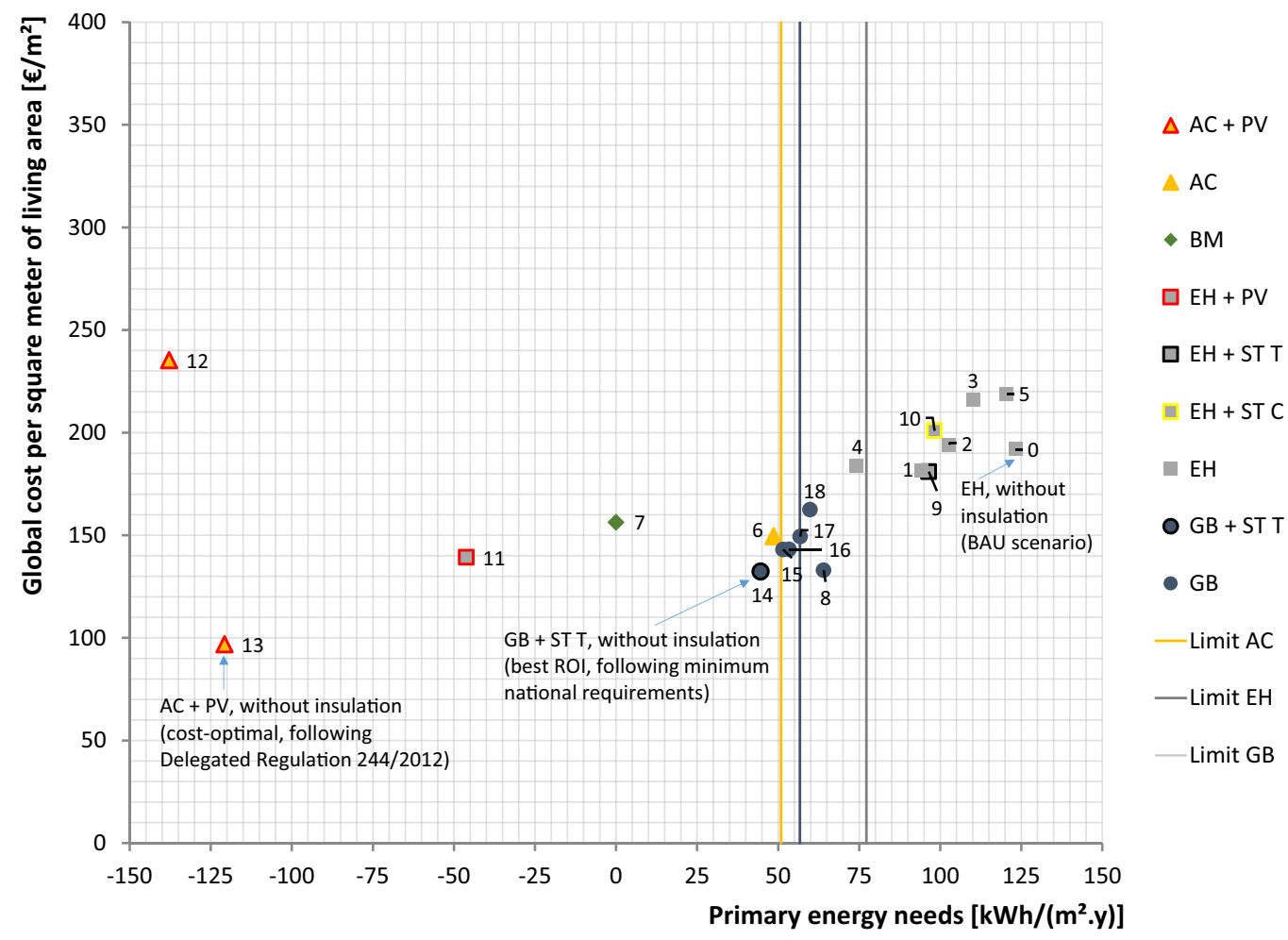

Fig. 8. Global cost $\left[€ / \mathrm{m}^{2}\right]$ and primary energy needs $\left[\mathrm{kWh} /\left(\mathrm{m}^{2} \mathrm{y}\right)\right]$ for 18 selected packages. 
Table 5

BAU scenario (package 0 ) and 18 selected packages.

\begin{tabular}{|c|c|c|c|c|c|c|c|c|c|c|c|}
\hline \multirow[b]{3}{*}{ Package } & \multicolumn{3}{|c|}{ Insulation } & \multicolumn{2}{|l|}{ Glazing } & \multicolumn{2}{|l|}{ Systems } & \multirow[t]{2}{*}{ Renewables } & \multirow{2}{*}{$\begin{array}{l}\text { Energy } \\
\text { Primary }\end{array}$} & \multirow{2}{*}{$\begin{array}{l}\text { Global cost } \\
\text { Financial }\end{array}$} & \multirow{2}{*}{$\begin{array}{l}\text { ROI } \\
\text { Financial }\end{array}$} \\
\hline & Roof & Walls & Floor & Windows & Panes & Heating & DHW & & & & \\
\hline & $t[\mathrm{~mm}]$ & $t[\mathrm{~mm}]$ & $t[\mathrm{~mm}]$ & $U\left[\mathrm{~W} / \mathrm{m}^{2}{ }^{\circ} \mathrm{C}\right]$ & gv̂i & Equipment & Equipment & Equipment & {$\left[\mathrm{kWh} / \mathrm{m}^{2} \mathrm{y}\right]$} & {$\left[€ / \mathrm{m}^{2}\right]$} & [30 years] (\%) \\
\hline 0 & - & - & - & 5.1 & 0.85 & $\mathrm{EH}$ & GWH 0.60 & - & 123 & 192 & - \\
\hline 1 & 60 & - & - & 5.1 & 0.85 & $\mathrm{EH}$ & GWH 0.60 & - & 94 & 181 & -59 \\
\hline 2 & - & 60 & - & 5.1 & 0.85 & $\mathrm{EH}$ & GWH 0.60 & - & 103 & 194 & -108 \\
\hline 3 & - & - & 80 & 5.1 & 0.85 & $\mathrm{EH}$ & GWH 0.60 & - & 110 & 216 & -163 \\
\hline 4 & 60 & 60 & - & 5.1 & 0.85 & $\mathrm{EH}$ & GWH 0.60 & - & 74 & 184 & -85 \\
\hline 5 & - & - & - & 1.87 & 0.58 & $\mathrm{EH}$ & GWH 0.60 & - & 121 & 219 & -197 \\
\hline 6 & - & - & - & 5.1 & 0.85 & $A C$ & GWH 0.78 & - & 49 & 150 & -20 \\
\hline 7 & - & - & - & 5.1 & 0.85 & BM & $\mathrm{BM}$ & - & - & 156 & -57 \\
\hline 8 & - & - & - & 5.1 & 0.85 & GB & GB & - & 64 & 133 & 275 \\
\hline 9 & - & - & - & 5.1 & 0.85 & $\mathrm{EH}$ & GWH 0.60 & ST T & 96 & 181 & -56 \\
\hline 10 & - & - & - & 5.1 & 0.85 & $\mathrm{EH}$ & GWH 0.60 & ST C & 98 & 201 & -122 \\
\hline 11 & - & - & - & 5.1 & 0.85 & $\mathrm{EH}$ & GWH 0.60 & PV & -46 & 139 & -67 \\
\hline 12 & 180 & 180 & 180 & 1.87 & 0.58 & $A C$ & GWH 0.78 & PV & -138 & 235 & -112 \\
\hline 13 & - & - & - & 5.1 & 0.85 & $A C$ & GWH 0.78 & PV & -121 & 97 & -56 \\
\hline 14 & - & - & - & 5.1 & 0.85 & GB & GB & ST T & 45 & 132 & 47 \\
\hline 15 & 60 & - & - & 5.1 & 0.85 & GB & GB & - & 52 & 143 & 18 \\
\hline 16 & 30 & - & - & 5.1 & 0.85 & GB & GB & - & 53 & 143 & 25 \\
\hline 17 & - & 30 & - & 5.1 & 0.85 & GB & GB & - & 57 & 149 & 6 \\
\hline 18 & - & - & 30 & 5.1 & 0.85 & GB & GB & - & 60 & 162 & -40 \\
\hline
\end{tabular}

Package 14 provides a ROI of $47 \%$, a $15.47 \%$ IRR, a simple payback of 6 years and an adjusted payback of 7 years. Package 8 offers the higher ROI over the 30 years, but does not comply with regulations. We must stress that package 14 can only be adopted because the building envelope does not undergo a "major renovation" given that the regulation in force (REH, 2013) establishes minimum requirements for thermal transmittance values in the envelope. This analysis shows the importance of evaluating the return on investment in a long-term rather than in the short-term perspective. It also shows that the cost-optimal approach is not enough to cover the information required by investors.

Fig. 8 shows the cost-optimal graph for the selected packages and regulatory limits to be met for primary energy needs, depending on the equipment used for heating.

For this reference building and the electric heater-EH, the limit stands at $77.23\left[\mathrm{kWh} /\left(\mathrm{m}^{2} \mathrm{y}\right)\right]$. For the air conditioner, the limit is $50.87\left[\mathrm{kWh} /\left(\mathrm{m}^{2} \mathrm{y}\right)\right]$ and it is $56.72\left[\mathrm{kWh} /\left(\mathrm{m}^{2} \mathrm{y}\right)\right]$ for the gas boiler and the biomass boiler. Thus, the BAU reference scenario (package 0 ) and packages $1-3,5,8-10$ and $17-18$ do not meet the regulations.

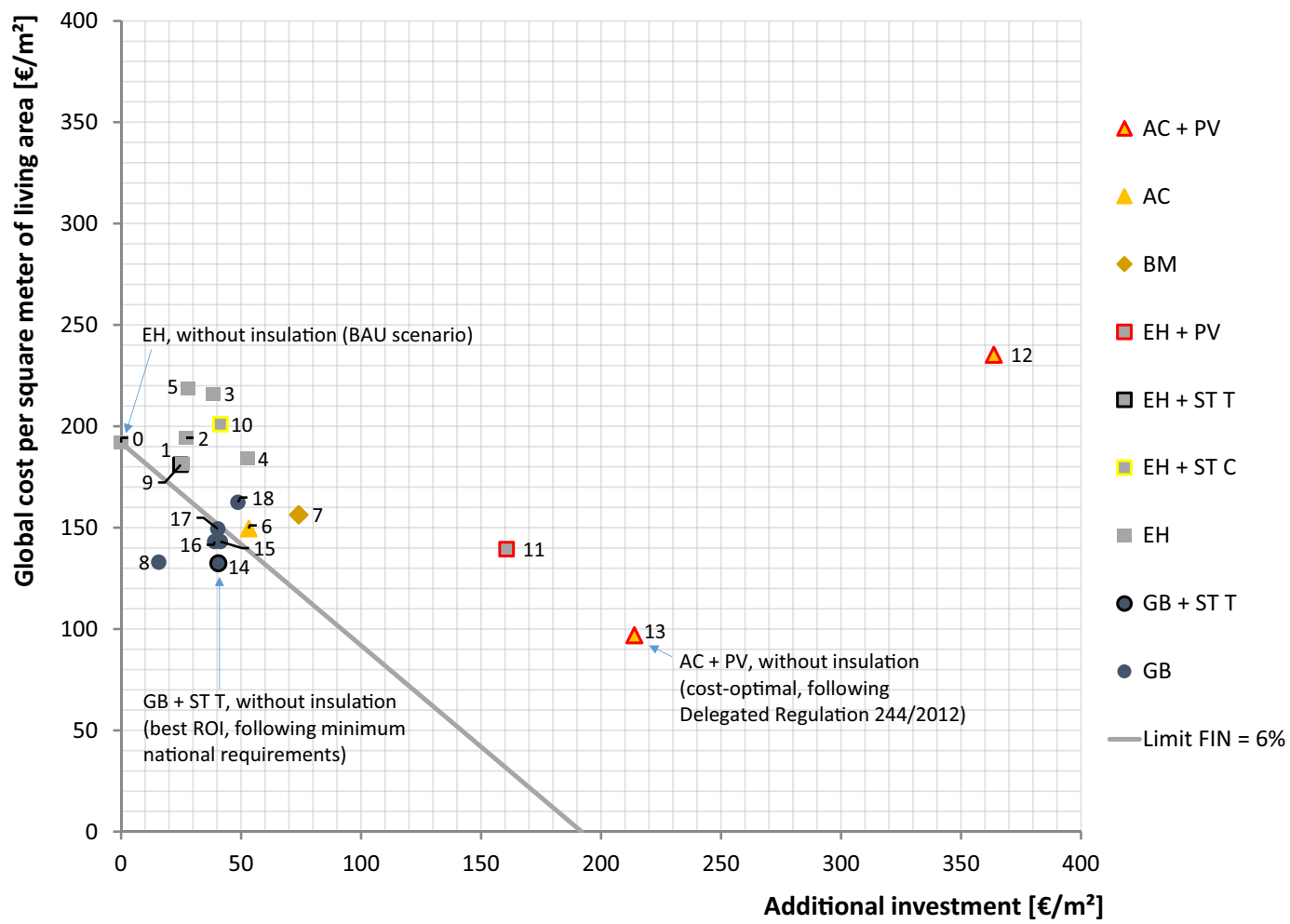

Fig. 9. Global cost $\left[€ / \mathrm{m}^{2}\right]$ and additional investment $\left[€ / \mathrm{m}^{2}\right]$ for 18 selected packages. 
Table 6

Summary of the analysis of real options.

\begin{tabular}{|c|c|c|c|c|c|c|c|}
\hline Measure: Investment in & $\begin{array}{l}\text { Lifecycle } \\
\text { (years) }\end{array}$ & $\begin{array}{l}\text { Contribution on the global } \\
\text { cost }\left[€ / \mathrm{m}^{2} .30 \text { years] }\right.\end{array}$ & $\begin{array}{l}\text { ROI for additional } \\
\text { investment }\end{array}$ & $\begin{array}{l}\text { Technical } \\
\text { uncertainty }\end{array}$ & $\begin{array}{l}\text { Economic } \\
\text { uncertainty }\end{array}$ & Risk & Option \\
\hline Photovoltaic panel (self-consumption) & 20 & -53 & $-67 \%$ & Middle & Middle & $\downarrow$ & Defer $^{\mathrm{a}}$ \\
\hline Solar thermal thermosyphon & 20 & -11 & $-56 \%$ & Low & Low & $\downarrow$ & bInvest \\
\hline Solar thermal forced circulation & 20 & 9 & $-122 \%$ & Low & Low & $\downarrow$ & Do not invest \\
\hline Air conditioner (heating), GWH (DHW) & 20 & -42 & $-20 \%$ & Low & High & $\downarrow$ & Do not invest \\
\hline Biomass boiler (heating, DHW) & 20 & -36 & $-57 \%$ & Low & High & $\downarrow$ & Do not invest \\
\hline Gas boiler (heating, DHW) & 20 & -59 & $275 \%$ & Low & High & $\downarrow$ & Invest ${ }^{\mathrm{b}}$ \\
\hline New windows & 40 & 27 & $-197 \%$ & Middle & Low & $\downarrow$ & Do not invest \\
\hline Insulation of the opaque envelope & 50 & $\downarrow \uparrow$ & $\downarrow \uparrow$ & Middle & Low & $\downarrow$ & Defer \\
\hline
\end{tabular}

a Although still having a negative ROI, the price of the equipment has fallen rapidly, determining that this investment option should be reassessed periodically.

b As shown in Table 5, the investment in ST T is necessary to sustain the investment in GB and fulfil the minimum national requirements; this package composition has a ROI of $47 \%$.

Fig. 9 shows the additional investment for the selected packages and the limit where the ROI is similar to the BAU scenario.

Packages 1-7, 9-13 and 18 have a worse economic performance than the BAU scenario, although packages 7 and 11-13 raise the building to the NZEB condition (nearly zero energy building), with primary energy demand below $15\left[\mathrm{kWh} /\left(\mathrm{m}^{2} \mathrm{y}\right)\right]$.

Regarding the real options that are available to investors, it is clear that the profitability depends on the heating system that is adopted. Investment in systems with high efficiency or low primary energy conversion factor can even allow the deferral of investment in insulation or replacing windows. The investment in the envelope represents a capital commitment for an extended period of time due to the long life cycles of these materials. Table 6 summarizes the analysis of real options.

The DHW system could be exchanged at the end of the life cycle of existing equipment; however, this represents a small reduction in the global cost. The combination of the gas boiler and the solar thermal thermosyphon system provides an immediate investment opportunity, since the building does not have architectural or technical restrictions, such as orientation of the building or shade. This option is better than the investment in an air conditioner in combination with a gas water heater, for this range of useful energy needs. The biomass system, here designed for heating and DHW in the entire the building, offers negative ROI, although it significantly reduces the primary energy needs. Possibly it can be a good alternative in the coming years, supplementing the solar thermal system, since the cost of firewood and pellets should remain low. This type of application requires further technical research.

Regarding the investment in photovoltaic panels, the available technology did not reveal itself profitable. Although it significantly reduces the primary energy needs, these equipment do not offer the attractive return on investment that was provided in the early years of the subsidized scheme. The reduction of the reference rates for micro generation since 2014 discourages the sale of surplus production to the grid by encouraging self-consumption (Decreto, 2014), which makes it an unaffordable investment. At this point, it is unknown whether the cost of initial investment could fall due to technological progress or what the reference tariff policy for the subsidized scheme will be in the coming years.

Assuming a discount rate of $3 \%$, a larger number of packages would present a satisfactory ROI, including the package AC + PV without insulation, as can be seen in Fig. 10. This confirms that credit lines with lower interest rates can encourage investment

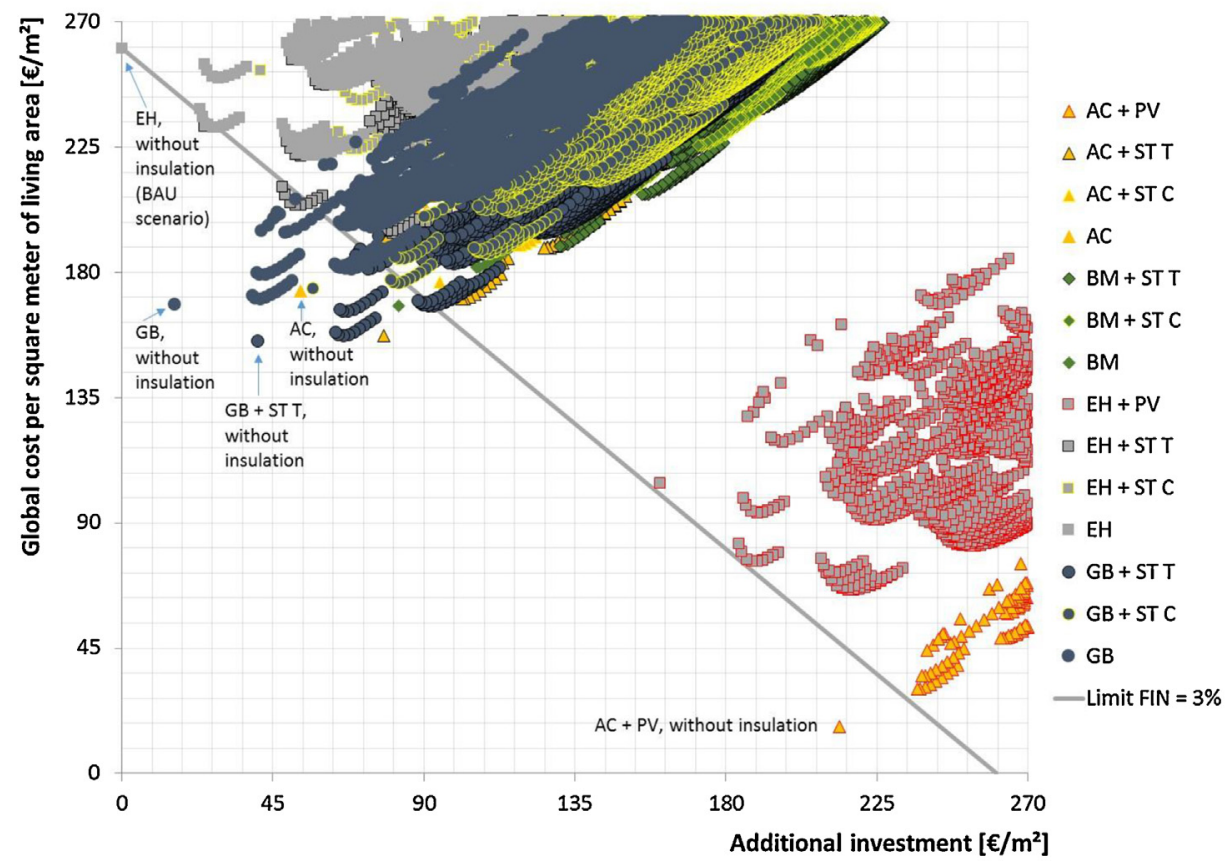

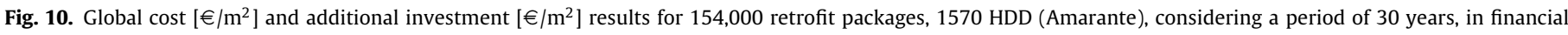
perspective (FIN = 3\%). 
in energy retrofit and efficiency measures with lower environmental impact, a fact also detected in previous studies (Tadeu, Rodrigues, Tadeu, Freire, \& Simões, 2015). However, GB+STT without insulation remains the best investment option, since GB without insulation does not meet the minimum national requirements.

\section{Conclusions}

This study assessed the relevance of applying the real options theory and return on investment criteria to the cost optimality of energy efficiency measures in the retrofit of buildings. Eighteen packages leading to 154,000 possible combinations of measures for a reference building were selected. The optimization problem was solved using a multi-objective evolutionary algorithm, GAEEB, taking into account the methodological framework proposed by the European Commission. The results from the real options perspective enabled to conclude that:

Regarding the profitability of the measures under analysis, the replacement of the DHW system presents an opportunity for exchanging at the end of the existing equipment life cycle. The combination of gas boiler with solar thermal system provides an immediate investment opportunity. This heating and DWH system is better than the investment in air conditioner coupled with gas water heater, for a low range of useful energy needs, as the ones considered in this study. The biomass system offers negative ROI, although it significantly reduces the primary energy needs; the photovoltaic panel did not show profitability.

Reducing the cost of capital through provision of public credit lines at rates below $6 \%$ may encourage investment in energy retrofit and efficiency measures that minimize the primary energy needs. In this scenario, a larger number of packages with lower environmental impact would have a satisfactory ROI, including renewables.

Regarding the energy retrofit of buildings, an analysis from the perspective of the theory of real options is fundamental because there are irreversibility issues and the possibility of deferral linked to the investment. Mainly in large investment projects, the value of operational flexibility and other strategic factors, in particular the possibility of deferral has to be added to NPV in the calculation process.

\section{Acknowledgments}

The first author (Sérgio Tadeu) is grateful for the financial support provided by Ciência sem Fronteiras Program and CNPq (Conselho Nacional de Desenvolvimento Científico e Tecnológico) in Brazil, through the doctoral degree grant 237489/2012-0. The second author would like to acknowledge the financial support from Coordination for the Improvement of Higher Education Personnel (CAPES, grant 012322/2013-00) and the Federal University of Ouro Preto. This work has been partially supported by the R\&D Project EMSURE (Energy and Mobility for Sustainable Regions) - CENTRO 070224 FEDER 002004 and project grants UID/MULTI/00308/2013 and MITP-TB/CS/0026/2013. The authors are also grateful for the support of Institute for Technological Research and Development in Construction Sciences (ITeCons) and ADENE for the data used in this research.

\section{References}

Asadi, E., Silva, M., Antunes, C., Dias, L., \& Glicksman, L. (2014). Multi-objective optimization for building retrofit: A model using genetic algorithm and artificial neural network and an application. Energy and Building, 81, 444-456.

Beume, N., Fonseca, C. M., Loípez-Ibáñez, M., Paquete, L., \& Vahrenhold, J. (2009). On the complexity of computing the hypervolume indicator. Evolutionary Computation IEEE Transactions, 13(5 (Oct)), 1075-1082.
Buildings Performance Institute Europe Implementing the cost-optimal methodology in EU countries. 2013.

Caccavelli, D., \& Gugerli, H. (2002). TOBUS, a European diagnosis and decision-making tool for office building upgrading. Energy and Buildings, 34, $113-119$

Chidiac, S., Catania, E., \& Morofsky, E. Foo. (2011). A screening methodology for implementing cost effective energy retrofit measures in Canadian office buildings. Energy and Buildings, 43, 614-620.

Chidiac, S., Catania, E., Morofsky, E., \& Foo, S. (2011). Effectiveness of single and multiple energy retrofit measures on the energy consumption of office buildings. Energy, 36, 5037-5052.

Christersson, M., Vimpari, J., \& Junnila, S. (2015). Assessment of financial potential of real estate energy efficiency investments-A discounted cash flow approach. Sustainable Cities and Society, 18, 66-73.

Coello, C., Lamont, G., \& Veldhuizen, D. (2007). Evolutionary Algorithms for Solving Multi-Objective Problem (2nd ed.). New York: Springer. http://dx.doi.org/10. 1007/978-0-387-36797-2

S. A. CYPE Ingenieros, Gerador de preços para construção civil, (2014). [Online]. Available: 〈http://www.geradordeprecos.info/〉 [Accessed: November, 2014].

Dall, O., Speccher, G., \& Bruni, A. E. (2012). The Green Energy Audit a new procedure for the sustainable auditing of existing buildings integrated with the LEED protocols. Sustainable Cities and Society, 3, 54-65.

Deb, K., Pratap, A., Agarwal, S., \& Meyarivan, T. (2002). A fast and elitis multiobjective genetic algorithm: NSGA-II. Evolutionary Computation IEEE, 6(2), 182-187.

Decreto-Lei n.o 153/2014 de 20 de outubro de 2014, Regime jurídico aplicável à produção de eletricidade por intermédio de unidades de microprodução, Ministério do Ambiente, Ordenamento do Território e Energia, Lisboa 2014.

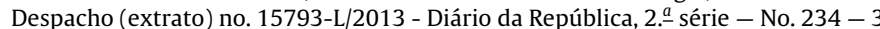
de dezembro de 2013.

DGEG. (2013). Cost-optimal Study for New Residential Buildings in Portugal. Lisbon: General Directorate for Energy and Geology.

Diakaki, C., Grigoroudis, E., \& Kolokotsa, D. (2008). Towards a multi-objective optimization approach for improving energy efficiency in buildings. Energy and Buildings, 40, 1747-1754.

Doukas, H., Nychtis, C., \& Psarras, J. (2009). Assessing energy-saving measures in buildings through an intelligent decision support model. Building and Environment, 44, 290-298.

EPBD (recast). (2010) Directive2010/31/EU of the European Parliament and of the Council of 19 May 2010 on the energy performance of buildings (recast), pp. L153/13-153/35.

Entidade Reguladora dos Serviços Energéticos - Portal ERSE (2009). [Online]. 〈http://www.erse.pt/pt/Paginas/home.aspx〉.

Delegated Regulation (EU). (2012). No 244/2012 of the Commission European of 16 January 2012, supplementing Directive 2010/31/EU of the European Parliament and of the Council on the energy performance of buildings. Official Journal of the European Union, 81, 18-36.

European Committee for Standardization, (2008). EN ISO 13790-Energy performance of buildings-Calculation of energy use for space heating and cooling.

European Committee for Standardization, (2007). EN 15459, Energy performance of buildings-Economic evaluation procedure for energy systems in buildings.

Eurostat-Half-yearly electricity and gas prices. Disponível: 〈http://epp.eurostat. ec.europa.eu/statistics_explained/index.php/Electricity_and_natural_gas_price_ statistics\#Electricity_prices_for_household_consumers). [Accessed: November, 2014].

Eurostat-EU Energy. (2013) Transport and GHG Emissions: Trends to 2050, Reference Scenario 2013.

Despacho (extrato) no. 15793-D/2013-Diário da República, 2. a série-No. 234 - 3 de dezembro de 2013.

O Parque habitacional e a sua reabilitação - análise e evolução 2001-2011 - INE (Instituto Nacional de Estatística) - Statistics Portugal, Lisbon 2013.

Instituto Nacional de Estatística. (2011). Inquérito ao Consumo de Energia no Sector Doméstico-2010. Portugal, Lisboa: Direcção Geral de Energia e Geologia.

Kannan, S., Baskar, S., McCalley, J. D., \& Murugan, P. (2009). Application of NSGA-II algorithm to generation expansion planning. Power System IEEE Transactions on, 24(1 (Feb)), 454-461.

Kumbaroglu, G., \& Madlener, R. (2012). Evaluation of economically optimal retrofit investment options for energy savings in buildings. Energy and Building, 49 327-334.

Marler, R., \& Arora, J. (2004). Survey of multi-objective optimization methods for engineering. Structural and Multidisciplinary Optimization, 26(6), 369-395.

Pindyck, R. (1988). Irreversible investment, capacity choice and the value of the firm. American Economic Review, 78(5), 969-985.

REH and RECS. (2013). DL 118/2013 - Regulamento de Desempenho Energético dos Edifícios de Habitação, Comércio e Serviços, Code of the Energy Performance of Buildings (residential and commercial). pp. 4988-5005. Lisbon: Ministry of Economy and Employment.

Robichek, A. A., \& Van Horne, J. C. (1967). Abandonment value and capital budgeting. The Journal of Finance, 22(4), 577-589.

Rysanek, A., \& Choudhary, R. (2013). Optimum building energy retrofits under technical and economic uncertainty. Energy and Building, 57, 324-337.

Silva, P. (1999). Técnicas de análise de investimentos-do VAL às opcões reais. Separata do Boletim de Ciências Económicas. Coimbra: Faculdade de Economia, Universidade de Coimbra. 
Soares, M. (1996). Algumas considerações de irreversibilidade e de diferimento de investimentos produtivos. Notas Económicas, 7, 90-98.

Soares, N.; Dias, L.; Ferreira, J.; Silva, P., Conceição, P. Energy efficiency of higher education buildings: a case study. International Journal of Sustainability in Higher Education, 14(5):n. d.

Tadeu, S., Rodrigues, C., Tadeu, A., Freire, F., \& Simões, N. (2015). Energy retrofit of historic buildings: Environmental assessment of cost-optimal solutions.

Journal of Building Engineering, 4, 167-176. 〈http://dx.doi.org/10.1016/j.jobe.2015.09. 009〉.

Verbruggen, A., Al Marchohi, M., \& Janssens, B. (2011). The anatomy of investing in energy efficient buildings. Energy and Buildings, 43, 905-914.
Wanxing, Sheng, Ke-yan, Liu, Yuan, Liu, Xiaoli, Meng, \& Yunhua, Li. (2015). Optimal placement and sizing of distributed generation via an improved nondominated sorting genetic algorithm II. Power Delivery IEEE Transactions on, 30 (2 (April)), 569-578.

Xingyi, Zhang, Ye, Tian, Ran, Cheng, \& Yaochu, Jin. (2015). An efficient approach to nondominated sorting for evolutionary multiobjective optimization. Evolutionary Computation IEEE Transactions on, 19(2 (April)), 201-213.

Zitzler, E., \& Thiele, L. (1998). Multiobjective optimization using evolutionary algorithms-A comparative case study. In Proceedings of the 5th International Conference Parallel Problem Solving from Nature (pp. 292-301). Berlin. Germany: Springer-Verlag. 